\title{
Chapter 14 \\ Role of Central Serotonin Receptors in Nicotine Addiction
}

\author{
Massimo Pierucci, Stephanie Chambers, Lucy Partridge, \\ Philippe De Deurwaerdère, and Giuseppe Di Giovanni
}

\begin{abstract}
Regulation of normal or abnormal behaviour is critically controlled by the central serotonergic systems. Recent evidence has suggested that serotonin (5-HT) neurotransmission dysfunction contributes to a variety of pathological conditions, including depression, anxiety, schizophrenia and Parkinson's disorders. There is also a great amount of evidence indicating that 5-HT signalling may affect the reinforcing properties of drugs of abuse by the interaction and modulation of dopamine (DA) function. This chapter is focused on one of the more addictive drugs, nicotine. It is widely recognised that the effects of nicotine are strongly associated with the stimulatory action it exhibits on mesolimbic DAergic function. We outline the role of 5-HT and its plethora of receptors, focusing on 5- $\mathrm{HT}_{2}$ subtypes with relation to their involvement in the neurobiology of nicotine addiction. We also explore the novel pharmacological approaches using 5-HT agents for the treatment of nicotine dependence. Compelling evidence shows that 5- $\mathrm{HT}_{2 \mathrm{C}}$ receptor agonists may be possible therapeutic targets for smoking cessation, although further investigation is required.
\end{abstract}

\author{
M. Pierucci, B.Sc. • G. Di Giovanni, Ph.D. $(\bowtie)$ \\ Faculty of Medicine, Department of Physiology \& Biochemistry, Malta University, \\ Tal-Qroqq, Msida MSD 2080, Malta \\ e-mail: giuseppe.digiovanni@um.edu.mt; massimo.pierucci@um.edu.mt \\ S. Chambers \\ Department of Medical Sciences, Exeter Medical School, \\ St. Luke's Campus, Exeter, EX1 2LU, Devon, UK \\ e-mail: sc505@exeter.ac.uk

\section{Partridge} \\ Department of Bioscience, Cardiff School of Biosciences, Sir Martin Evans Building, \\ 2 Museum Avenue, Cardiff CF10 3AX, South Glamorgan, UK \\ e-mail: PartridgeLM@ cardiff.ac.uk \\ P. De Deurwaerdère, Ph.D. \\ Centre National de la Recherche Scientifique, Institut des Maladies \\ Neurodégénératives (UMR CNRS 5293), Universitè de Bordeaux, \\ 146 rue Léo Saignat, Bordeaux Cedex 33076, France \\ e-mail: deurwaer@u-bordeaux.fr
}


Keywords Serotonin receptors - Nicotine addiction - Serotonergic system - Neurotransmission $\bullet$ Parkinson's $\bullet$ 5-HT $\bullet$ 5-HT receptors $\bullet$ Nicotine $\bullet$ DRN $\bullet$ MRN

- Serotonergic projections $\bullet$ Smoking cessation treatment $\bullet$ Serotonergic drugs

\section{Introduction}

There are a large number of scientific publications on serotonin (5-HT)-containing neurons in the brain and their role in normal and pathological behaviour $[1,2]$. Disturbances in 5-HT function have been linked to many psychiatric and behavioural conditions, particularly anxiety and mood disorders [3]. This is not surprising, due to the complexity of 5-HT function, as it has a multitude of receptors and widespread 5-HT neuronal innervation and is coupled with diverse signalling pathways $[4,5]$.

Rather than exhibiting direct effects on cell bodies, the effects of 5-HT are usually indirect, involving the modulation of complex neuronal circuitry. This modulation is generally subtle as it is dependent on a number of other neurotransmitter baseline activities and their activation. The increased availability of 5-HT receptor knockout mice $(\mathrm{KO})$ and molecular understanding of the 5-HT receptors have encouraged a great amount of new research in recent years [5, 6].

Dysfunction of 5-HT neurotransmission contributes to the pathophysiology of a variety of neuropsychiatric disorders such as schizophrenia, depression and drug abuse $[2,7,8]$. Therefore, developing selective and specific pharmacological agents for 5-HT receptor subtypes has given researchers the opportunity to gain insight into the roles these receptors play in various disorders of the brain and clinicians' new therapies with better efficacy and fewer side effects [9-13].

This chapter focuses on the functional role of 5-HT and its receptors in nicotine addiction. It reviews the anatomy of the 5-HT system and explores the distribution of 5-HT receptors, and the physiological and pharmacological aspects of these receptors in the central nervous system (CNS). Previously published experimental data is reviewed showing the relationship between agents specifically targeted to $5-\mathrm{HT}_{2}$ receptors and the effect of nicotine. Consideration of the potential use of these agents for treatment of cessation of tobacco smoking and subsequently nicotine addiction is also included.

\section{Serotonergic Systems}

5-HT has been suggested to have both excitatory and inhibitory roles in the nervous system; therefore there is great difficulty in elucidating the precise nature of modulation [14]. The reason for this difficulty in classification may be due to the number of different roles exhibited by the 5-HT receptor subtypes in association with different neurotransmitter systems [14-16]. Due to the significance of 5-HT receptor control 
on dopamine (DA) activity and the relationship between this and pathophysiology of specific DA-related diseases such as schizophrenia, depression, Parkinson's disease (PD) and drug abuse, this area has received a great amount of attention [17].

The distribution of 5-HT in organisms gives rise to the description of two 5-HT subsystems, those being central and peripheral [18]. 5-HT is found in many different tissues such as the heart, lungs, blood vessels, platelets and pancreatic tissue. The amount of 5-HT present in the CNS is relatively low. The peripheral subsystem contains most of the 5-HT (90\%), which is around $10 \mathrm{mg}$ in the human body, and is found mainly in mucosal enterochromaffin cells of the gastrointestinal (GI) tract $[19,20]$. Overall, 5-HT expression of all neurons in the enteric nervous system (ENS) reaches 2-20\% [21, 22].

Research into 5-HT began in the ENS to accentuate the high concentrations of the neurotransmitter in this region, more specifically in the GI tract. Between 1937 and 1940, the Italian researcher Vittorio Erspamer identified a substance they called enteramine, a "gut-stimulating factor" found in the mucosa of the intestine, later found to be 5-HT [23]. In the late 1940s a research group led by Page also purified the same substance from beef blood, highlighting that it had vasoconstrictive activity. Page named this as "... serotonin, which indicates that its source is serum and its activity is one of causing constriction ..." [24]. Twarog and Page [25] performed a sensitive bioassay which used extracts of mammalian brain and detected 5-HT. Brodie and colleagues [26] suggested that 5-HT may serve as a neurotransmitter in the CNS, which was later supported further by the work of Costa and Aprison [27] who discovered that it was in fact present in the human brain. This resulted in one of the most pivotal discoveries in science and the birth of a new branch of neuroscience [28].

The serotonergic system has a topographical organisation corresponding to the functional and anatomical properties that they exhibit [29], and is one of the mammalian brain's diffusively organised projective systems. The majority of serotonergic neurons reside in the brainstem, being particularly present in the raphe nuclei, part of the reticular formation. The 5-HT cells in this region are multipolar, with size and orientation being extremely different to other complex axonal systems in the CNS. They send projections virtually to all the CNS areas from limbic structures, basal ganglia, cerebral cortex and brainstem to the spinal cord grey matter. Upon the discovery that the brainstem contained these 5-HT cell groups, Dahlstrom and Fuxe [30] produced a system to code these groups based on the rat brainstem. These morphologically heterogeneous cells have been divided into nine nuclei groups from B1 (the most caudal cell cluster) to B9 (Fig. 14.1). These can then be combined into two major groups, the caudal and rostral serotonergic groups. The caudal group, also referred to as the inferior group, is situated in the medulla and consists of three separate nuclei. These nuclei project to the grey matter of the spinal cord and are called the nucleus raphe magnus (NRM, group B5), the nucleus raphe obscures (NRO, groups B1, B2 and B3) and the nucleus raphe pallidus (NRP, group B4). The rostral group, also known as the superior group, is positioned in the pons/mesencephalon, and consists of two main nuclei: the first being the dorsal raphe nucleus (DRN, groups B6 and B7), which in the human brain is thought to contain about 235,000 neurons [31], and the second being the median raphe nucleus (MRN, cell group B8). 


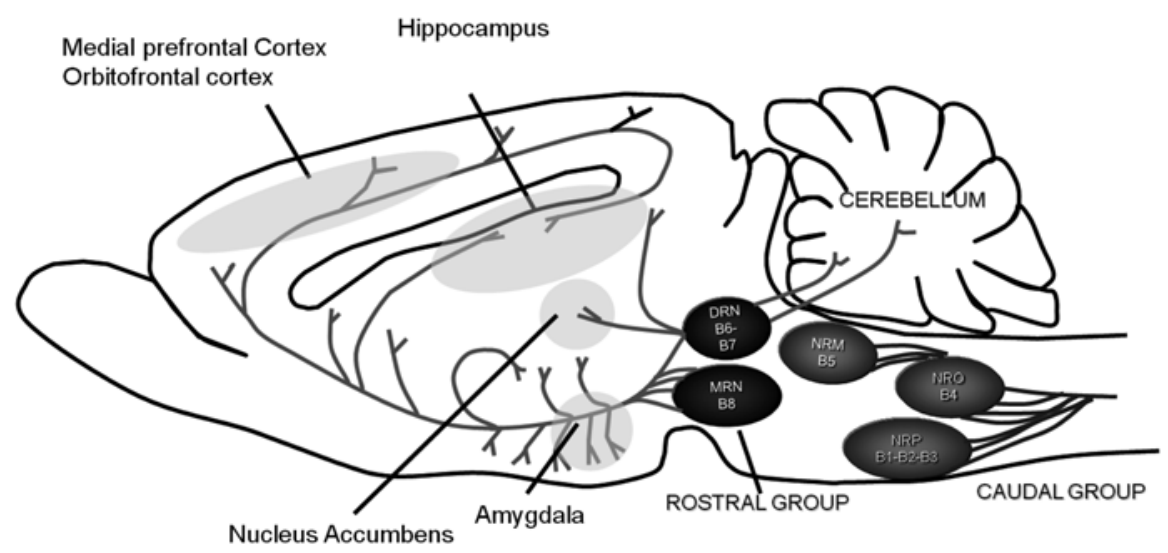

Fig. 14.1 Midsagittal view of the rat brainstem with serotonin-immunoreactive cell body groups. The ovals encompass the two major subdivisions of the brain serotonergic system. $D R N$ dorsal raphe nucleus, $M R N$ medial raphe nucleus, $N R M$ nucleus raphe magnus, $N R O$ nucleus raphe obscurus. Cell groups B1 to B9 according to the terminology of Dahlström and Fuxe [176]

\subsection{Ascending Serotonergic Projections}

The DRN and MRN are the main subdivisions of the raphe nucleus, providing innervation to nearly all structures of the CNS [32-37]. The primary targets of 5-HT projections lie in the forebrain and spinal cord, with the ascending projection collaterals reaching many different regions of the brain such as the cerebral cortex, basal ganglia, limbic system and diencephalon. These projections primarily travel in the medial forebrain bundle from which many axons extend toward other fibre pathways in order to reach their target areas. Innervation patterns vary greatly between the different areas of the forebrain and are extremely specific. Fibre density in the cortex varies between layers; in primates the cortex receives a particularly dense 5-HT innervation in layer IV [35, 38]. The striatum also has a very dense innervation, along with the hypothalamus, septal area and specific areas of the thalamus.

Most areas of the brain contain an overlapping innervation coming from the DRN and MRN, apart from the dorsal hippocampus, the suprachiasmatic nucleus, the olfactory bulb and the medial septum nucleus, which receive 5-HT innervation from only the MRN. On the other hand, the corpus striatum, the globus pallidus, the lateral septum nucleus, the amygdala and most of the prefrontal cortex (PFC) are all preferentially innervated by the DRN with the substantia nigra pars reticulata $(\mathrm{SNr})$ receiving the largest DRN 5-HT innervation in the CNS $[39,40]$. The ventral part of the hippocampus, the nucleus accumbens (NAcc) and various nuclei in the thalamus receive innervation from both the DRN and MRN [32]. Moreover, there are extensive serotonergic connections between the two main serotonergic nuclei of the brainstem [41]. 
It is noteworthy that all the brain areas involved in drug addiction [33, 34, 37], such as the ventral tegmental area (VTA) and substantia nigra (SN), including their terminal fields, receive projections from 5-HT containing cell bodies in the raphe nuclei (Fig. 14.1) [34, 35, 42, 43], confirming the implication of 5-HT in drug abuse.

\subsection{Descending Serotonergic Projections}

Descending serotonergic projections to the spinal cord originate from the medullary raphe nuclear complex, forming a network of fibres with a strong density of 5-HT axons throughout the grey matter [44]. More specifically, the dorsal horn, ventral horn motor nuclei and thoracic cord intermediolateral column have extremely dense serotonergic innervation. Additional regions receiving strong 5-HT input include the central grey matter and the ependyma of the central canal (containing a 5-HT nerve plexus). As highlighted above, the main origin of 5-HT afferents is the raphe nuclei, although other minor projections are also present. These are shown to originate from B9 cells scattered in the pontomesencephalic reticular area of the brain and also from cells in the medial longitudinal fasciculus [44, 45].

\section{5-HT Receptors}

The diversity of effects produced by 5-HT when administered in the brain is due to the large variety of receptors to which it binds. These are classified into seven main classes, those being $5-\mathrm{HT}_{1}$ to $5-\mathrm{HT}_{7}$. These are then further divided into 14 different receptor types, classified by the means of pharmacological profiling, cDNA-deduced primary sequencing and signal transduction methods [4, 5, 16, 46]. Most 5-HT receptors are metabotropic G-protein-coupled receptors (GPCRs), excluding the ionotropic 5- $\mathrm{HT}_{3}$ receptors. The 5-HT GPCRs act through intracellular signalling pathways in order to depolarise or hyperpolarise their host cell [16]. 5-HT receptors may have synergistic or opposing activity. For example, in the administration of cocaine, blocking the 5- $\mathrm{HT}_{2 \mathrm{~A}}$ receptors attenuated some of the effects of cocaine, whereas blocking the $5-\mathrm{HT}_{2 \mathrm{C}}$ receptors caused an enhancement in some of the behavioural effects induced by cocaine [47-49]. The behavioural aspects linked to impulsivity are also mediated by the opposing actions of these two $5-\mathrm{HT}_{2}$ receptor subtypes [49]. It is of interest to note that the same 5-HT receptor subtypes located in different neuronal regions can act synergistically; that is, the 5- $\mathrm{HT}_{1 \mathrm{~A}}$ receptors that are located both on raphe cell bodies and postsynaptically in limbic regions control impulse flow through the excitability of 5-HT raphe neurons and the postsynaptic neurons [50]. 


\section{Serotonergic Involvement in the CNS Effects of Nicotine}

It has been suggested in several studies that 5-HT is one of the more important neurotransmitter systems involved in the reinforcing aspects of drugs of abuse [51-54]. The physiological and pharmacological effects of nicotine are complex. Interactions between nicotinic acetylcholine receptors (nAChRs), gamma-aminobutyric acid (GABA), glutamate (GLU) and DA in the VTA are involved in the reinforcing effects of nicotine (for reviews, see [55, 56] and Chap. 15). For instance, the activation of mesolimbic DA neurons is essential in the behavioural effects of nicotine, including locomotor activity and reinforcement [57-59].

5-HT hypofunction is a defining factor in depression [60]. A number of animal and human studies suggest that changes in 5-HT transmission can contribute to the symptoms of nicotine withdrawal such as anxiety and depression [61] and an increased risk of suicide and self-harm [62]. Consistently, nicotine has been shown to manifest antidepressant effect on the user [63]; indeed prevalence of smoking is much higher amongst people suffering with depression [64].

Previous studies into the molecular properties of nAChRs in the DRN have shown the presence of $\alpha 4, \alpha 7$ and $\beta 2$ subunits [65-68]. The $\alpha 7$ subunit was found to be highly expressed on DRN neurons with a large diameter of 15-25 $\mu \mathrm{m}$ and colocalised with tryptophan hydroxylase [69]. It was also found on neurons with a smaller diameter of 5-10 $\mu \mathrm{m}$ that are usually GABAergic [66]. The cholinergic input to the serotonergic DRN cells is sustained by the pedunculopontine tegmentum (PPTg) neurons [70]. In vitro electrophysiology studies have shown that the neuronal activity of 5-HT neurons is influenced by nicotine. Most 5-HT neurons of the DRN increase their action potential firing rate when nicotine is administered, which results in an overall increase in 5-HT output to its target tissues [71-73]. The excitability of these DRN neurons is also indirectly stimulated by their synaptic drive, which is influenced by nicotinic presynaptic heteroreceptors. Indeed, the effects of nicotine include the enhancement of excitatory glutamatergic input to DRN-NAcc projection neurons, and the positive or negative modulation of inhibitory GABAergic input to the same subset. Nonetheless, in vivo systemic nicotine has been shown to decrease neuronal firing in the majority of DRN neurons, increasing it in only a small subset of neurons $[74,75]$. When nicotine was applied locally to the DRN it evoked 5-HT release [76], while systemic nicotine produced only a small and restricted increase in 5-HT [77]. Thus, the 5-HT firing inhibition may be a secondary effect, depending on 5-HT release from the somatic dendrites. Some in vivo data are in conflict with in vitro results. It is important to consider that 5-HT neurons are strongly impacted by the arousal state (sleep-waking) [78]; therefore there is a possibility that the effects in the DRN neurons, upon nicotine administration in vivo, may be influenced by factors such as anaesthesia and the time of day that the experiment takes place. Moreover, acute exposure of DRN neurons to nicotine may therefore cause direct depolarisation and indirect synaptic modulation. Given the excitatory effects of nicotine on DRN neurons, it is likely that 5-HT contributes to the rewarding effects of nicotine. 
A number of the behavioural effects induced by nicotine may be mediated by the 5-HT neurotransmitter system [61]. In this context, Summers and colleagues [79] showed that nicotine, as well as the nicotinic agonist RJR-2403, significantly increased cortical release of 5-HT in rats. Since there has been no observation of nicotinic binding sites being present on 5-HT axon terminals in the cortex [80], the increased release of 5-HT might be due to the DRN projections to the cortex that express nAChRs in their soma [79].

In addition, $\left[{ }^{3} \mathrm{H}\right] 5-\mathrm{HT}$ release from striatal synaptosomes is increased by ACh, nicotine and the nicotinic receptor agonists epibatidine and cytosine; this effect can be inhibited by administration of the non-competitive nicotinic receptor antagonist mecamylamine [81]. The release of 5-HT into striatal slices due to nicotine exposure showed an increase over a number of days; for example a significant enhancement after 10 days of nicotine treatment has been described [82]. Acute and chronic nicotine administration increased striatal 5-HT release in freely moving rats only when they were exposed to stress, likely by stimulating presynaptic nicotinic receptors in the striatum [83]. Nicotinic receptor agonists such as 1,1-dimethyl-4phenylpiperazinium (DMPP), lobeline and nicotine have been shown to increase $\left[{ }^{3} \mathrm{H}\right] 5-\mathrm{HT}$ release in hippocampal slices in the rat; however cytisine, epibatidine and nicotine had no effect in others [84, 85]. Reuben and Clarke [81] also found supporting evidence that nicotine had no effect on 5-HT release from the cerebral cortex or hippocampal synaptosomes. Furthermore, there is conflicting evidence on the effects of chronic treatment with nicotine and the concentration of 5-HT in the dorsal hippocampus, with both decreases [86] and increases [87] being described. The duration of treatment is likely to be a factor in the effect of nicotine on the brain's 5-HT system. Although, in one study, 5-HT levels in the hypothalamus increased following both acute and chronic nicotinic administration, rates of 5-HT synthesis were not affected [61].

A number of pieces of research suggest that the release of 5-HT in the spinal cord is both directly and indirectly controlled through multiple nAChR populations. One nAChR population, located on 5-HT terminals, might have an excitatory effect on 5-HT outflow. Conversely, a second $\mathrm{nAChR}$ population, expressed on GABAergic interneurons and tonically activated by endogenous ACh, inhibits 5-HT release in the spinal grey matter [61].

Nicotine is the main alkaloid found in nicotiana plants (95-97\%) and is largely responsible for the deleterious effects of tobacco including addiction. Two factors have to be taken into account when considering the mode of which nicotine is administered. First of all, a number of minor alkaloids are found in the plant (cotinine, anabasine, nornicotine, tabagisine, myosmine). These minor tobacco alkaloids have similar structural and pharmacological activity compared to nicotine, although they are generally less potent $[88,89]$. Nornicotine and cotinine also play a role as major metabolites of nicotine [89]. Intravenous infusion of nicotine, combined with five minor alkaloids found in tobacco smoke (anabasine, nornicotine, anatabine, cotinine and myosmine), increased locomotor activity and behavioural sensitisation following self-administration in rats [90]. A tobacco extract specifically containing nicotine and these alkaloids was more potent to enhancing striatal DA release in 
freely moving rats compared to pure nicotine. The potentiation was not observed in the nucleus accumbens [91]. These experiments, using an extract, confirm that the striatum plays an important role in the psychoactive properties of nicotine and/or tobacco (see below). Interestingly, the extract of alkaloids from the plant is more potent in inhibiting DRN neuronal firing rate compared to pure nicotine [75].

Second, smoking tobacco generates a very high number of molecules $(>4,000)$ that are absorbed which can also modulate the psychoactive properties of nicotine. It has been reported for instance that some of these compounds block the monoamine oxidases A and B (MAOA and MAOB), mitochondrial enzymes involved in the degradation of monoamines. These compounds may be relevant to tobacco addiction because their co-administration in rats has been shown to dramatically enhance the DA effects of nicotine and the motivation to self-administer nicotine [92]. The blockade of MAO-A and MAO-B, by limiting the degradation of 5-HT at the terminals, could favour 5-HT output and reinforce the dichotomy between the ability of nicotine to reduce DRN neuronal firing rate and to enhance 5-HT release at some terminals. However, this remains to be investigated.

On the whole, there is good supporting evidence from a number of sources to conclude that nicotine elicits an increase in 5-HT neuronal activity and an overall release of 5-HT in several target tissues in the brain including the DRN [76].

\section{5-HT Receptors and the Rewarding Properties of Nicotine}

In regard to the involvement of the various 5-HT receptor subtypes in nicotine use and dependence, very little work has been done to attribute the effects of administered ligands on these receptors, to the behavioural effects of nicotine. The 5-HT ${ }_{1 \mathrm{~A}}$, $5-\mathrm{HT}_{2 \mathrm{~A}}, 5-\mathrm{HT}_{2 \mathrm{C}}, 5-\mathrm{HT}_{3}, 5-\mathrm{HT}_{4}$ and $5-\mathrm{HT}_{6}$ subtypes are considered to be the most likely targets involved in nicotine use and dependence. In this chapter we focus on the $5-\mathrm{HT}_{2}$ receptor class.

\section{$5.1 \quad 5-H_{2 A}$ Receptors}

$5-\mathrm{HT}_{2 \mathrm{~A}}$ receptors are the predominant receptor subtypes in cortical areas, but are also present in DA-rich areas such as the NAcc, striatum, VTA and SN [93-95]. Such receptors are situated mainly postsynaptically; for instance $5-\mathrm{HT}_{2 \mathrm{~A}}$ receptors are found on pyramidal neurons, as well as GABAergic interneurons in the PFC $[96,97]$. 5- $\mathrm{HT}_{2 \mathrm{~A}}$ receptors can also be found on DAergic and non-DAergic cells of the VTA and SN [97-99]. 5- $\mathrm{HT}_{2 \mathrm{~A}}$ receptors are therefore seen, due to their anatomical distribution, as a good candidate for the modulation of DA-mediated functions.

A number of behavioural effects of nicotine are altered by 1-(2,5-dimethoxy-4iodophenyl)-2-aminopropane (DOI) administration. For example, a study showed that DOI did not alter the acute stimulant action of nicotine, yet it did inhibit the 
development of sensitisation to the locomotor stimulant effect when nicotine was administered repeatedly in rats [100]. When given to mice, DOI was shown to avert the initial locomotion suppression induced by nicotine [101]. DOI administration mitigated the discriminative stimulus properties of nicotine, effects that were inhibited by $5-\mathrm{HT}_{2 \mathrm{~A}}$ receptor antagonists, but not by $5-\mathrm{HT}_{2 \mathrm{C}}$ receptor antagonists $[101,102]$. These results provide evidence that $5-\mathrm{HT}_{2 \mathrm{~A}}$ receptor stimulation may oppose some of the behavioural effects of nicotine. Drug discrimination studies have shown a relationship between DOI and lysergic acid diethylamide (LSD) [103], with 5-HT $\mathrm{H}_{2 \mathrm{~A}}$ receptor stimulation by LSD and other drugs being recognised to induce hallucinations [104]. Even with this evidence, and although DOI can reduce some behavioural effects of nicotine, it is difficult to apply this to the treatment of nicotine dependence in humans with $5-\mathrm{HT}_{2 \mathrm{~A}}$ receptor agonists. $5-\mathrm{HT}_{2 \mathrm{~A}}$ receptor blockade inhibits the extracellular increase of DA when induced by amphetamine and cocaine $[105,106]$. This effect can also be seen on a behavioural level, in which the selective 5- $\mathrm{HT}_{2 \mathrm{~A}}$ receptor antagonist M100907 attenuates locomotor stimulant effects of cocaine, amphetamine and other such psychomotor stimulants $[47,48,107]$. The $5-\mathrm{HT}_{2 \mathrm{~A}}$ receptors resident in the VTA appear to be integral in modulating psychostimulant-induced behaviours mediated by the mesocorticoaccumbens circuit. Indeed local infusion of M100907 to the VTA blocked amphetamine- and cocaine-induced locomotion [47, 106]. Consistently, it has recently been shown that vulnerability of adult male rats to hyperactivity, induced by cocaine, is enhanced following virally mediated overexpression of 5- $\mathrm{HT}_{2 \mathrm{~A}}$ receptors in the VTA [108]. Due to this evidence, and the relationship between the VTA and reinforcing effects of nicotine, it may be expected that $5-\mathrm{HT}_{2 \mathrm{~A}}$ receptor antagonists would modify some of the behavioural effects observed following the administration of nicotine. However, phasic but not tonic activation of $5-\mathrm{HT}_{2 \mathrm{~A}}$ receptors appear to have inhibitory influence on the nicotine cue, since their pharmacological stimulation by DOI attenuates the discriminative stimulus effects of nicotine, while their blockade by M100907 was ineffective [102]. Recently, Levin and co-authors [109] showed that the 5- $\mathrm{HT}_{2 \mathrm{~A} / 2 \mathrm{C}}$ receptor antagonist, ketanserin, significantly decreased nicotine self-administration. This effect is likely to be due to 5- $\mathrm{HT}_{2 \mathrm{C}}$ receptor blockade since, unlike ketanserin, the selective 5- $\mathrm{HT}_{2 \mathrm{~A}}$ receptor antagonist M100907 did not alter nicotine self-administration on the fixed ratio schedule 5 (FR5) or progressive ratio schedules of reinforcement [110]. The reinstatement of nicotineseeking behaviour elicited by cues previously associated with self-administered nicotine or by priming injections of nicotine were both reduced by activation of $5-\mathrm{HT}_{2 \mathrm{C}}$ receptors and by blockade of $5-\mathrm{HT}_{2 \mathrm{~A}}$ receptors.

Collectively, these results show that while a $5-\mathrm{HT}_{2 \mathrm{C}}$ receptor agonist and a $5-\mathrm{HT}_{2 \mathrm{~A}}$ receptor antagonist have differing effects on nicotine self-administration, they both reduce the reinstatement of nicotine-seeking behaviour [110]. This evidence shows that the reinforcing, psychomotor stimulant and discriminative effects of nicotine are not affected by $5-\mathrm{HT}_{2 \mathrm{~A}}$ receptor blockade, but that $5-\mathrm{HT}_{2 \mathrm{~A}}$ receptors may have a role in inducing nicotine-seeking behaviour. However, since M100907 reduced the reinstatement of cocaine-seeking behaviour, induced by cocaine or cocaine-associated cues [110], it can be inferred that its effects are not nicotine specific. 


\section{$5.25-H_{2 C}$ Receptors}

5-HT has an influential role on the effects of many drugs of addiction and of particular interest is its action via the $5-\mathrm{HT}_{2 \mathrm{C}}$ receptor subtype in modulating the effects of nicotine $[1,51,54,111] .5-\mathrm{HT}_{2 \mathrm{C}}$ receptors are located on DA cell bodies and GABAergic interneurons in the VTA area, observed by mapping studies $[112,113]$. Furthermore, there is evidence that shows how central DA function is influenced by $5-\mathrm{HT}_{2 \mathrm{C}}$ receptors $[10,114-116]$, whereas blockage of the 5- $\mathrm{HT}_{2 \mathrm{~A}}$ receptor has consistently no effect on reinforcing the discriminative or the psychomotor stimulatory effects of nicotine. Administration of RO 60-0175, a selective 5- $\mathrm{HT}_{2 \mathrm{C}}$ receptor agonist [117], in in vivo electrophysiological and neurochemical studies, induced a decrease in both the burst firing activity and basal firing rate of VTA DA neurons and decreased both striatal and accumbal DA release [118-121]. Moreover, the administration of the selective 5- $\mathrm{HT}_{2 \mathrm{C} / 2 \mathrm{~B}}$ receptor antagonist, SB 206553 [122], and the selective 5- $\mathrm{HT}_{2 \mathrm{C}}$ receptor antagonist, SB 242084 [123], both showed the opposite effect on DA neuronal activity and DA release [115, 121, 124, 125]. Additionally, the use of RO 60-0175 to stimulate 5- $\mathrm{HT}_{2 \mathrm{C}}$ receptors in the VTA caused suppression of the stress-stimulated DA outflow in the rat PFC [126], whereas SB 242084 was found to potentiate it [126]. Alongside this, the phencyclidine-induced increase in accumbal DA release was enhanced by SB 242084 pretreatment [127]. Collectively, this evidence suggests that these receptors play a role in mediating the evoked DA release. In line with these studies, the increase in morphine-induced DA release in the NAcc was inhibited by stimulation of 5- $\mathrm{HT}_{2 \mathrm{C}}$ receptors in freely moving rats [96]. Furthermore, DA release in the NAcc and corpus striatum, in addition to the DA neuronal firing rate in the VTA and the substantia nigra pars compacta (SNc) induced by morphine, was enhanced by SB 206553 administration [128]. The effects of these agonists were blocked by SB 242084. The pharmacological stimulation of the 5- $\mathrm{HT}_{2 \mathrm{C}}$ receptor with RO 60-0175 and WAY163909 (another agonist of the $5-\mathrm{HT}_{2 \mathrm{C}}$ receptor) has been shown to attenuate the discriminative stimulus effects induced by nicotine [102, 129]. SB 242084 alone induced some nicotine-induced responses $(\sim 30 \%)$, although it did not alter the nicotine cue. Overall, these studies show that pharmacological stimulation of the $5-\mathrm{HT}_{2 \mathrm{C}}$ receptors causes an attenuation of the discriminative stimulus response, although the tonic activation of these receptors does not influence the subjective effects of nicotine.

Investigations carried out by independent groups into the role of a $5-\mathrm{HT}_{2 \mathrm{C}}$ receptor agonist, RO 60-0175, in nicotine self-administration, showed that on a fixed-ratio/60-s timeout (FR5/ TO-60s) and FR5 schedule, RO 60-0175 caused a diminished response rate for nicotine [110, 130], and this effect was blocked by SB 242084 [110]. Priming injections of nicotine were administered to induce reinstatement of the response; this response was reduced by $5-\mathrm{HT}_{2 \mathrm{C}}$ receptor agonism by $\mathrm{RO}$ 60-0175 and lorcaserin (a relatively selective 5- $\mathrm{HT}_{2 \mathrm{C}}$ receptor agonist which has received the US Food and Drug Administration (FDA) approval as an anti-obesity drug) and by 5- $\mathrm{HT}_{2 \mathrm{~A}}$ antagonism using M100907 [110, 131]. The observed diminished response rate for nicotine occurred over a similar range of doses to that 
observed for cocaine self-administration [132], which was also reduced by $5-\mathrm{HT}_{2 \mathrm{C}}$ manipulation [110, 132-134]. Moreover, the stimulation of 5- $\mathrm{HT}_{2 \mathrm{C}}$ receptors by RO 60-0175 reduced the previous nicotine-induced self-administration and nicotine-induced hyperactivity $[130,135]$. In addition, a reduction in nicotineinduced self-administration and hyperactivity was observed with ketanserin [109] and lorcaserin [136].

Mixed results have been obtained from studies on nicotine-induced conditioned place preference involving the effects of $5-\mathrm{HT}_{2 \mathrm{C}}$ receptor agonists such as $\mathrm{RO}$ 60-0175, WAY161503 and WAY163909. In mice, RO 60-0175 blocked both nicotine-induced place preference and the conditioned place preference observed with tetrahydrocannabinol (THC) [137]. However, in rats, nicotine-induced place preference was not blocked by WAY161503, even at doses which induced locomotion [138]. It is important to consider that the comparison of these studies is difficult, as it is unclear whether these discrepancies are due to the different $5-\mathrm{HT}_{2 \mathrm{C}}$ receptor agonists or the different species on which they were carried out.

Interestingly RO 60-0175 was also able to block sensitisation to nicotine (occurring after repeated exposure to the drug) as well as reduce nicotine-induced hyperlocomotion and the operant response for nicotine [130]. Two separate studies using $5-\mathrm{HT}_{2 \mathrm{C}}$ agonists found that the stimulation of locomotion by nicotine in rats with prior nicotine exposure was blocked by both WAY161503 [138] and WAY163909 [139], and furthermore that the administration of SB 242084 reinstated this effect of nicotine.

Two studies by Esposito and colleagues [140, 141] were conducted to investigate whether DA is involved in the behavioural effects of the interaction of RO 60-0175 and nicotine-induced hyperlocomotion and reward. At 1 and $3 \mathrm{mg} / \mathrm{kg}$ doses of RO 60-0175, the increase in DA release induced by the administration of acute nicotine was prevented in the corpus striatum but not in the NAcc [140]. However, enhanced DA release, induced by chronic nicotine administration, was prevented both in the corpus striatum and NAcc by the same doses of RO 60-0175 [140]. The selective 5- $\mathrm{HT}_{2 \mathrm{C}}$ receptor antagonists, SB 242084 and SB243213, both inhibited the effects of RO 60-0175 [140]. At the doses used, it is probable that both SB 242084 and SB243213 specifically block $5-\mathrm{HT}_{2 \mathrm{C}}$ receptors in the brain. Therefore, it can be inferred that blockage of the hyperlocomotive and rewarding effects of nicotine by RO 60-0175 [132] are likely to be due to its ability to inhibit mesolimbic DA function. Differences in the effects of acute and repeated exposure to nicotine on the central 5-HT system may explain why RO 60-0175 had varying effects on DA release in the NAcc, although further investigations are needed to elucidate this point. The efficacy of the 5- $\mathrm{HT}_{2 \mathrm{C}}$ agonists could be indirect by acting against DA transmission within the basal ganglia. For instance, RO 60-0175 $(1 \mathrm{mg} / \mathrm{kg})$ has been shown to enhance the activity of GABAergic neurons of the VTA neurons [142] while DA transmission may favour their inhibition [143, 144]. Also, RO 60-0175 $(1 \mathrm{mg} / \mathrm{kg})$ enhanced the phasic and excitatory impact of the prefrontal but not the motor cortex stimulation on the activity of GABAergic neuron of the SNr [145]. The efficacy of the $5-\mathrm{HT}_{2 \mathrm{C}}$ agonists could be more directly related to changes of DA indices especially because $5-\mathrm{HT}_{2 \mathrm{C}}$ receptors control well an increase in DA release associated with an 
increase in DA neuron firing rate [96, 128, 146]. Indeed, Pierucci et al. [141] tested the hypothesis that the effects seen in the NAcc and striatum with stimulation of $5-\mathrm{HT}_{2 \mathrm{C}}$ receptors and nicotine were due to changes in DA neuronal activity (see Figs. 14.2, 14.3 and 14.4). RO 60-0175 pretreatment prevented the enhancement in DA neuronal firing rate elicited by acute nicotine administration in the SNc, in both drug-naive and chronically treated rats, but was devoid of any significant effect in the VTA. Moreover, RO 60-0175 significantly reduced the stimulatory effect on the VTA DA neurons, induced by acute nicotine, both in drug-naive and chronically treated rats. However, after repeated administration of nicotine there were no changes observed in the nicotine-induced excitation of DA neurones in the VTA (see Figs. 14.3 and 14.4). Thus it seems that the chronic administration of nicotine does not potentiate the nicotine effect previously observed, via increasing the firing activity of mesolimbic DAergic neurons, but via another mechanism. Moreover, in rats previously treated with chronic nicotine, administration of acute nicotine caused a significant increase in the burst firing activity of DA neurons in the VTA but not in the SNc [141]. It has been postulated that after repeated nicotine administration, tolerance to the stimulatory effect of nicotine occurs in the nigrostriatal but not in the mesolimbic DAergic system, a hypothesis also supported by the presented data.

In further agreement, studies have recently revealed that there is a reduced 5-HT turnover and an increase in 5- $\mathrm{HT}_{2 \mathrm{C}}$ receptor sensitivity after the repeated administration of nicotine. However the up-regulation of 5- $\mathrm{HT}_{2 \mathrm{C}}$ receptors is only observed following repeated treatment with this alkaloid. Furthermore, the expression of nicotine-induced locomotor sensitisation is counteracted by repeated administration of citalopram, a selective 5-HT re-uptake inhibitor [147]; therefore it can be hypothesised that the development and expression of sensitisation to mesolimbic DA system, by repeated administration of nicotine, can be prevented by the activation of the 5-HT system. This effect could be beneficial to smoking cessation therapies as the activation of the 5-HT system could lead to the extinction of nicotine-induced rewarding effect on the DAergic system. The activation of the 5- $\mathrm{HT}_{2 \mathrm{C}}$ receptors was previously associated with the effect of stimulating the GABAergic neurons which negatively impact on DA-containing neurons in the SNc and the VTA [1]; therefore it is speculated that the inhibitory action of RO 60-0175 on nicotine-induced DA release [140] and in the neuronal activity changes [141] might be also partially mediating this effect in a similar manner. Collectively, these results show that

Fig. 14.2 (continued) nicotine administration on single DAergic neurons' firing rates compared to controls (saline, $100 \mu \mathrm{l}$ i.v., at arrows), while the graphs below report the cumulative dose-response curves showing the mean percentage changes $( \pm$ S.E.M.) in firing rate after either nicotine or saline administration. Arrows indicate the time of nicotine or saline injections; apomorphine (Apo), a D1/ D2 receptor agonist, was injected (10-30 $\mu \mathrm{g} / \mathrm{kg}$, i.v.) at the end of most of the experiments to confirm the DAergic identity of recorded neurons (adapted from [141] with permission). (b) Time course of nicotine $(1 \mathrm{mg} / \mathrm{kg}$, i.p.)-induced effect on DA terminal release in both the striatum and nucleus accumbens. Changes in DA extracellular levels were assessed using in vivo microdialysis on freely moving animals. The arrows indicate the time of injection of either nicotine or saline (adapted from [140] with permission) 

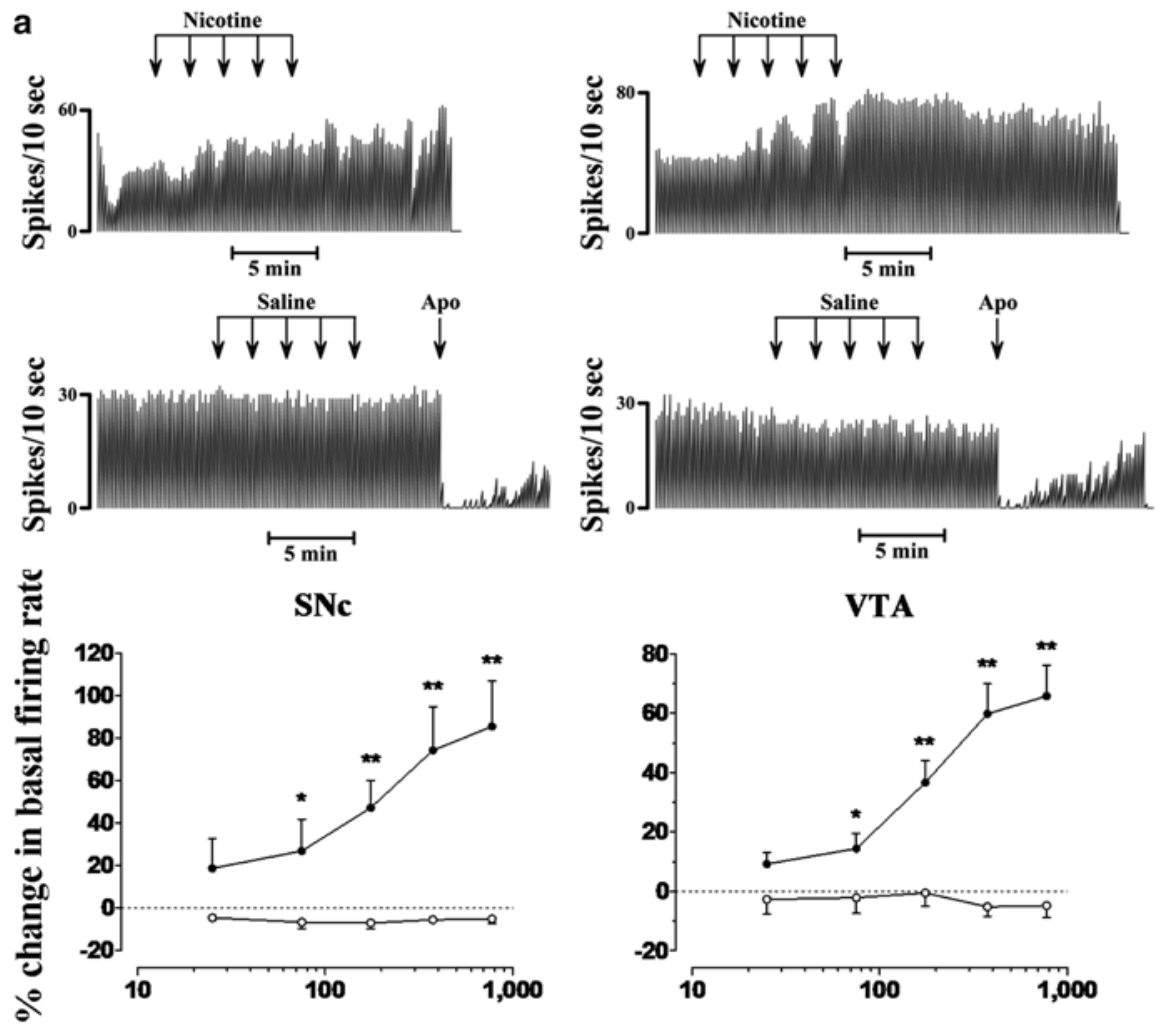

VTA

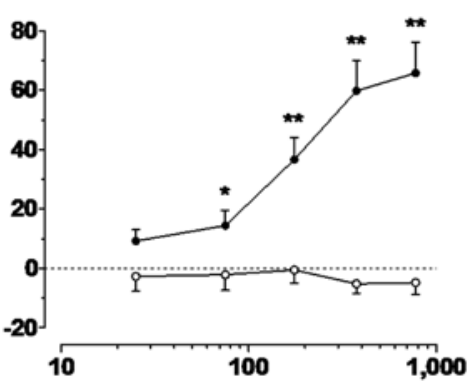

Cumulative doses of nicotine $(\mu \mathrm{g} / \mathrm{kg}, i . v$.)
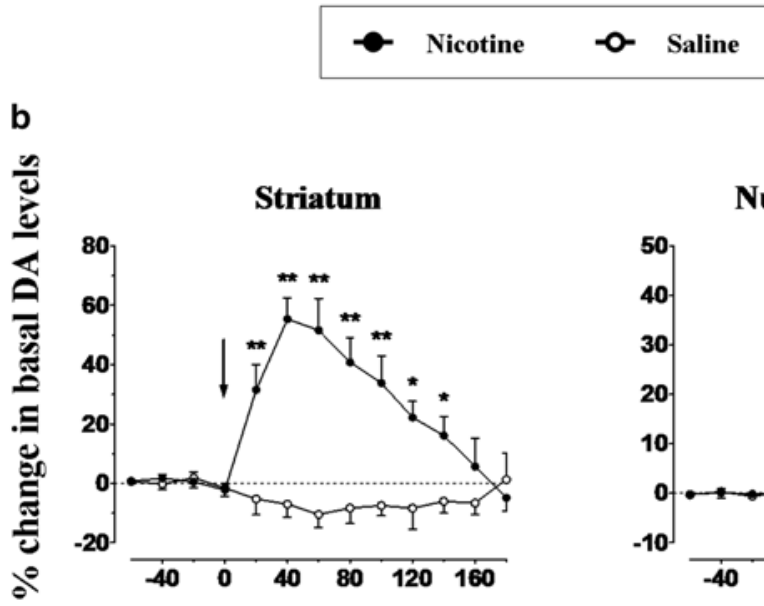

\section{Time (min)}

Fig. 14.2 Systemic administration of nicotine increases the activity of the both nigro-striatal and meso-corticolimbic DAergic systems of drug-naive rats in vivo. (a) The injection of cumulative doses of nicotine $(25-775 \mu \mathrm{g} / \mathrm{kg}$, i.v.) increased the firing rate of DA neurons recorded using in vivo single-unit extracellular recording technique. The rate meters on top show the effect of 

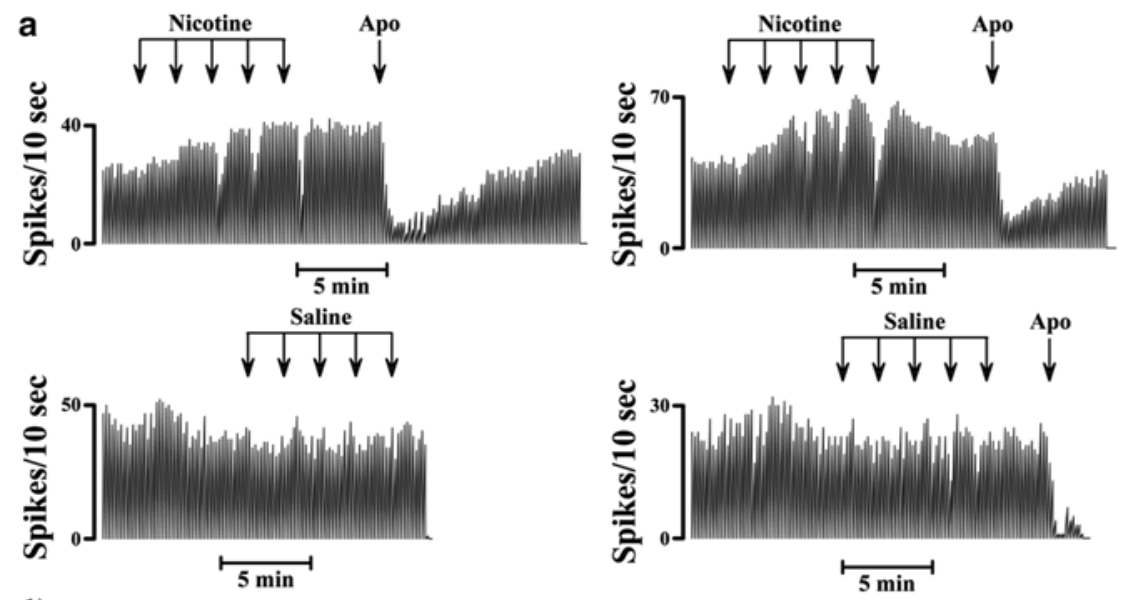


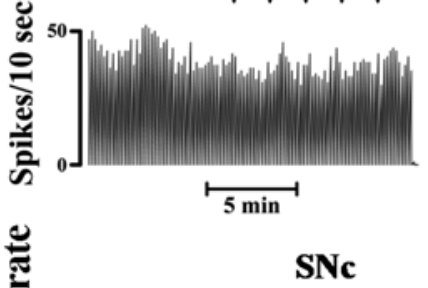

\section{VTA}
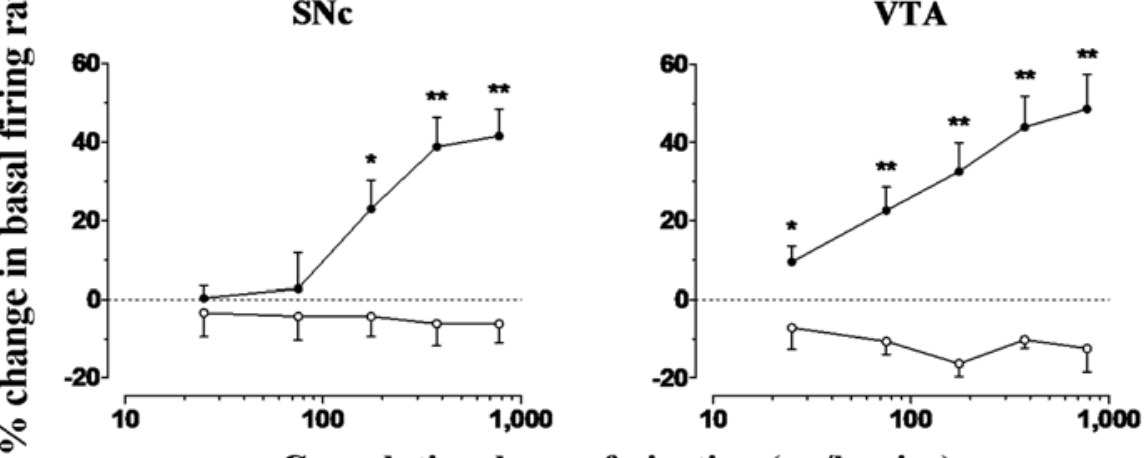

Cumulative doses of nicotine $(\mu \mathrm{g} / \mathrm{kg}, i . v$.)

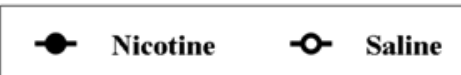

b

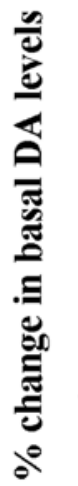

Striatum

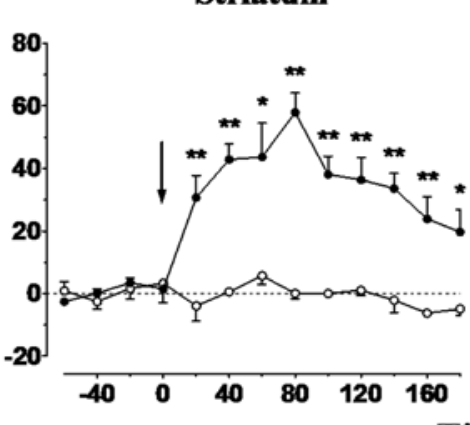

Nucleus Accumbens

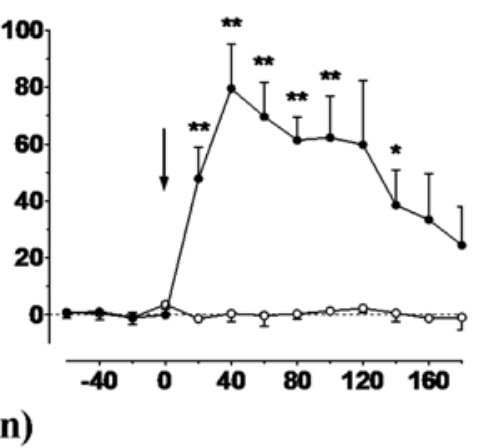

Fig. 14.3 Systemic administration of nicotine increases the activity of both nigro-striatal and meso-corticolimbic DAergic systems in vivo of rats chronically treated with nicotine $(1 \mathrm{mg} / \mathrm{kg}$, i.p.) for 10 consecutive days. (a) The injection of cumulative doses of nicotine $(25-775 \mu \mathrm{g} / \mathrm{kg}$, i.v.) 
5- $\mathrm{HT}_{2 \mathrm{C}}$ receptor agonists reduce the stimulatory, discriminative and perhaps reinforcing effects of nicotine as well as reduce the impact of nicotine on electrophysiological and neurochemical indices of DA function (Fig. 14.4).

The cessation of chronic nicotine use can produce aversive effects, including both motivational and somatic withdrawal symptoms such as nicotine craving, anxiety, reduced concentration, irritability, depressed mood and an increased appetite [148]. These withdrawal effects are considered to be the main factors in the maintenance of the tobacco habit in human smokers. The role of 5-HT and the 5- $\mathrm{HT}_{2 \mathrm{C}}$ receptor in nicotine withdrawal and its negative effects is gradually being elucidated; recently it was shown that both RO 60-0175 and M100907 reversed the resultant depressive-like behaviour from nicotine withdrawal [149]. Conversely, preliminary results show that RO 60-0175 and lorcaserin do not reduce mecamylamine-precipitated somatic signs of withdrawal in nicotine-dependent rats [131]. 5- $\mathrm{HT}_{2 \mathrm{C}}$ drugs could be potentially beneficial to relieve the aversive symptoms induced by nicotine cessation when combined with adjunct smoking cessation therapies.

\section{Smoking Cessation Treatment with the Use of Serotonergic Drugs}

In the USA and Europe only approximately $6 \%$ of those who quit smoking succeed in abstaining, despite $70 \%$ of the population trying to quit at least once; therefore relapse is deemed to be the limiting factor in successful smoking cessation [150]. Half of relapses occur within 2 days of smoking cessation, and the majority occur within 3 months of quitting [151]. Environmental and sensory stimuli associated with smoking can act as conditioning stimuli which re-enforces smoking behaviour in humans [152]; in both active and former smokers the motivation to smoke can be increased on exposure to such cues (i.e. produce cue-induced craving) [153, 154]. All these factors are important considerations when generating the overall picture of smoking addiction.

Smoking is estimated to reduce the overall life expectancy of an individual by 8 years and reduce the amount of "healthy" years by 12 [150]; therefore the development of beneficial therapies to facilitate smoking cessation and to reduce relapse

\footnotetext{
Fig. 14.3 (continued) increased the firing rate of DA neurons recorded using in vivo single-unit extracellular recording technique. The rate meters on top show the effect of nicotine administration on single DAergic neurons' firing rates compared to controls (saline, $100 \mu 1$ i.v., at arrows), while the graphs below report the cumulative dose-response curves showing the mean percentage changes $( \pm$ S.E.M.) in firing rate after either nicotine or saline administration. Arrows indicate the time of nicotine or saline injections; apomorphine (Apo), a D1/D2 receptor agonist, was injected $(10-30 \mu \mathrm{g} / \mathrm{kg}$, i.v. $)$ at the end of most of the experiments to confirm the DAergic identity of recorded neurons (adapted from [141] with permission). (b) Time course of nicotine (1 mg/kg, i.p.)-induced effect on DA terminal release in both the striatum and nucleus accumbens. Changes in DA extracellular levels were assessed using in vivo microdialysis on freely moving animals. The arrows indicate the time of injection of either nicotine or saline (adapted from [140] with permission)
} 

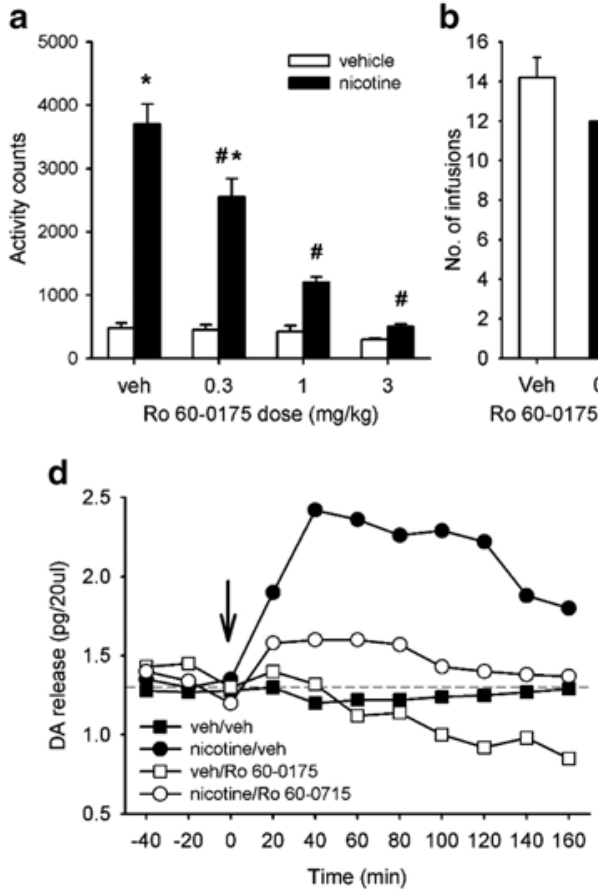

C

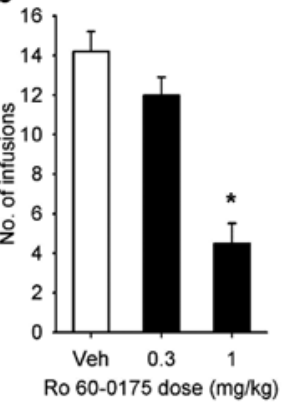

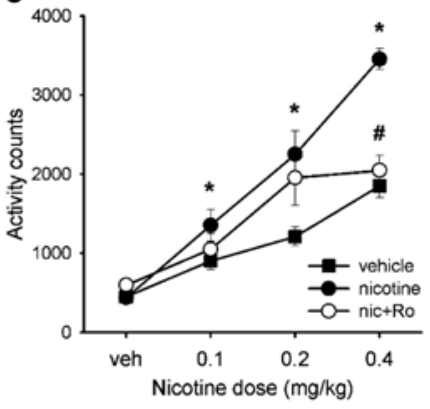

e

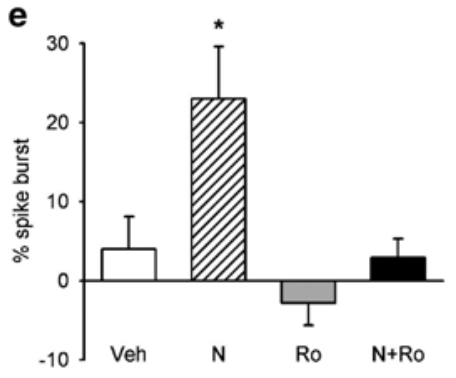

Fig. 14.4 Summary of evidence supporting a potential role for $5-\mathrm{HT}_{2 \mathrm{C}}$ receptor agonists as treatments for smoking cessation. (a) Effect of RO 60-0175 on hyperactivity induced by nicotine $(0.4 \mathrm{mg} / \mathrm{kg} \mathrm{s.c})$, in rats previously sensitised to nicotine (ten daily injections of nicotine $0.4 \mathrm{mg} /$ kg s.c). ${ }^{\#} p<0.05$ vs. vehicle/vehicle pretreatment, ${ }^{*} p<0.05$ vs. vehicle/nicotine pretreatment. (b) Effect of RO 60-0175 on nicotine self-administration. Nicotine $(0.03 \mathrm{mg} / \mathrm{infusion})$ was available for $1 \mathrm{~h}$ each day, under an FR5TO 1-min schedule of reinforcement. (c) Effect of chronic treatment with vehicle, nicotine $(0.4 \mathrm{mg} / \mathrm{kg} \mathrm{s.c})$ or nicotine $(0.4 \mathrm{mg} / \mathrm{kg} \mathrm{s.c})+\mathrm{RO} 60-0175(1 \mathrm{mg} / \mathrm{kg} \mathrm{s.c})$ on locomotor activity produced by nicotine $(0-0.4 \mathrm{mg} / \mathrm{kg}$ s.c). Prior nicotine exposure resulted in an enhanced locomotor response to nicotine $(* p<0.05)$ that was blocked by RO 60-0175 $\left({ }^{*} p<0.05\right)$. (d) Time course of the effect of acute nicotine $(1 \mathrm{mg} / \mathrm{kg}$ i.p.) on extracellular dopamine levels in the nucleus accumbens measured by microdialysis. Rats were treated for 10 days with nicotine $(1 \mathrm{mg} / \mathrm{kg}$ i.p.) prior to the microdialysis experiment. Rats were treated with either vehicle or RO $60-0175$ ( $1 \mathrm{mg} / \mathrm{kg}$ i.p) $20 \mathrm{~min}$ before nicotine $(1 \mathrm{mg} / \mathrm{kg}$ i.p) or vehicle (indicated by arrow). Nicotine increased extracellular dopamine release in the nucleus accumbens. This effect was significantly attenuated by RO 60-0175 pretreatment. (e) Effect of nicotine (i.v.) and RO 60-0175 $(0.1 \mathrm{mg} / \mathrm{kg}$ i.v. $)$ on the firing pattern of VTA dopamine neurons in rats treated for 10 days with nicotine $(1 \mathrm{mg} / \mathrm{kg}$ i.p.). The data represent the mean \pm SEM difference between the percentages of spikes occurring in bursts during baseline vs. post-drug periods. The data show that nicotine increases burst firing of VTA dopamine neurons, and that this effect is blocked by RO 60-0175. Figure reproduced from [53] with permission

is of great interest. Nicotine replacement therapy (NRT) and the non-nicotine-based therapies are the two types of pharmacological interventions that have been approved by the US FDA for smoking cessation. NRT involves the replacement of nicotine with other nicotine-based formulations, which are less harmful than tobacco, in the 
form of chewing gum, transdermal patches or inhalers [155]. Non-nicotine-based therapy is represented mostly by bupropion, an atypical antidepressant $[156,157]$, or varenicline, the $\alpha 4 \beta 2 *$ nAChR partial agonist [158]. Comparing these therapies, NRTs have proved to be the least effective for smoking cessation, with varenicline being the most effective, followed by bupropion [159]. The increased efficacy of varenicline is likely to be due to its ability to both aid smoking cessation and prevent relapse; varenicline partially activates the $\alpha 4 \beta 2 *$ nAChRs (also activated by smoking); therefore when paired with smoking cessation it effectively mimics the effects of smoking and, additionally, if a relapse occurs varenicline prevents the full activation of $\alpha 4 \beta 2 *$ nAChRs [160].

Bupropion was the first non-NRT to be used for smoking cessation, although it later appeared to be a non-competitive antagonist of several nAChRs. The sustained-release bupropion formulation, the phenylaminoketone atypical antidepressant agent, was approved in the USA in 1997 by the FDA. It is thought that the ability of bupropion to block DA and noradrenaline (NA) reuptake, although modestly, accounts for its ability to treat nicotine dependence, but its exact mechanism of action is still unclear [156]. Moreover, the clinical efficacy of bupropion as a smoking cessation aid may be due to its antagonistic activity at nAChRs [161]. Threohydroxybupropion and hydroxybupropion are the major metabolites of bupropion, and they inhibit DA and NA reuptake to the same or lesser extent as bupropion [156]. Bupropion and hydroxybupropion administered in a dose-dependent manner were found to reduce the firing rate of noradrenergic neurons in the locus coeruleus, similar to tricyclic antidepressants (TCAs); the $\alpha_{2}$-adrenergic antagonist yohimbine reversed this action [162]. In vitro, bupropion diminished the tonic inhibition of DA neurones via a reduction in the GABAergic transmission to these neurones, and also greatly reduced the effects of nicotine on DA neuron excitability [163]. The antidepressant action of bupropion may be aided, in the absence of nicotine, by these increases in DA neuron excitability during treatment [163]. Overall, this suggests that the antidepressant effect of bupropion may be partially due to a DAergic or a noradrenergic counterpart. Additionally, in the DRN, bupropion caused a sustained increase in the basal firing activity of 5-HT neurons [164], but currently the significance of the mechanism of action of bupropion in this latter effect, in a clinical setting, is unknown.

Varenicline, its trade name being Chantix in the USA and Champix in Canada, Europe and other countries, was developed by Pfizer and introduced as a novel smoking cessation aid with a high efficacy for the $\alpha 4 \beta 2 \mathrm{nAChR}$, in $2006[158,160]$. Varenicline affects monoaminergic neurotransmission by modulating release of DA, NA and 5-HT. Varenicline selectively binds to $\alpha 4 \beta 2 *$ nAChRs with high affinity, similar to nicotine-evoked DA release in the rat NAcc due to its interaction with $\alpha 4 \beta 2 *$ nAChRs in the VTA $[158,160,165]$. Varenicline competitively blocks nicotine from binding to the nAChRs, and thus stimulates the mesolimbic DA system.

In the rat, only high doses of varenicline $(10 \mathrm{mg} / \mathrm{kg})$ produce increases in PFC DA and NA release [166], whereas $1 \mathrm{mg} / \mathrm{kg}$ produces no significant changes in extracellular levels of 5-HT, NA and DA [167]. The effect of a $10 \mathrm{mg} / \mathrm{kg}$ dose, that is associated with very high brain concentrations of $>1 \mu \mathrm{M}$, may be due to the interaction of 
varenicline with several other $n A C h R$ subtypes other than $\alpha 4 \beta 2 \mathrm{nAChRs}$. Varenicline has a very low affinity for 5-HT receptors and the 5-HT transporter; its lack of interaction with central 5-HT receptors and its inability to block 5-HT reuptake mean it is unable to increase 5-HT; thus its in vitro properties explain why it has little effect on cortical monoamine release. Varenicline is also a full agonist of 5- $\mathrm{HT}_{3 \mathrm{~A}}$ receptors; however, despite having a modest affinity for these receptors, the brain concentrations of therapeutic unbound varenicline are hypothesised to be insufficient to activate central 5- $\mathrm{HT}_{3 \mathrm{~A}}$ receptors. Moreover varenicline does not inhibit MAO-A, the enzyme which metabolises 5-HT, and does not bind to DA receptors that modulate 5-HT release. Additionally, when varenicline is combined with one or both antidepressant drugs it did not cause significant effects on the increased neurotransmitter levels, induced by sertraline and/or clorgyline [167]. Despite the findings that varenicline is more effective than bupropion and NRT in recent meta-analyses $[159,168]$, there was an observed increase in neuropsychiatric symptoms in those taking varenicline, causing the FDA to issue an alert [169]. These neuropsychiatric symptoms include behavioural changes, agitation, depressed mood, hostility and suicidal thoughts. This has led to a large clinical trial to reassess the safety of varenicline, evaluating the neuropsychiatric adverse events; this is expected to be complete by 2017. Nevertheless, a recent prospective cohort study showed that there is no evidence of an increased risk of suicidal behaviour in patients prescribed varenicline or bupropion compared with those prescribed nicotine replacement therapy [62]. These findings should be reassuring for users and prescribers of smoking cessation medicines.

Antidepressants are the most common drug, in the class of non-nicotine-based drugs, to be effective in aiding smoking cessation. TCAs which inhibit NA and 5-HT such as nortriptyline [170-172] and doxepin [173] have been proposed to be of benefit in aiding smoking cessation, in combination with behavioural treatment.

Due to the primary role of 5-HT in the modulation of smoking behaviour and nicotine reward, selective serotonin reuptake inhibitors (SSRIs) have been studied as a safer and better tolerated antidepressant to TCAs. Indeed, anticholinergic activity and frequent lethality in overdose are associated with TCAs; thus these significant aversive side effects mean other substances are being targeted for the beneficial therapeutic use [61, 111]. Fluoxetine, a prototypical SSRI, was shown to have equivocal results to TCAs and may relieve most of the adverse withdrawal symptoms experienced by smokers with a history of depression [174]. The 5- $\mathrm{HT}_{1 \mathrm{~A}}$ receptor is involved in anxiolytic activity; therefore buspirone, a $5-\mathrm{HT}_{1 \mathrm{~A}}$ receptor partial agonist, has been studied for its use as an anti-anxiolytic in order to treat nicotine addiction. Buspirone administration stimulates the $5-\mathrm{HT}_{1 \mathrm{~A}}$ receptors leading to a reduction in presynaptic release of 5-HT, which appears to mediate anxiolytic effects. Unfortunately buspirone was shown to have little effect in aiding smoking cessation, shown by a placebocontrolled clinical trial [175]. 5- $\mathrm{HT}_{2 \mathrm{C}}$ receptor agonists could also potentially be utilised for the treatment of smoking cessation [49, 111, 129]. Weight gain is viewed as a contributory factor in preventing smoking cessation; therefore the role of 5- $\mathrm{HT}_{2 \mathrm{C}}$ receptor agonists in decreasing feeding behaviour and thus preventing weight gain could be of particular interest in beneficially treating nicotine dependence [176] (Table 14.1). 
Table 14.1 Effects of varenicline, bupropion, RO 60-0175 and lorcaserin against various nicotinemotivated behaviours in the rodent (adapted from [111] with permission)

\begin{tabular}{l|l|l|l|l}
\hline & Varenicline & Bupropion & RO 60-0175 & Lorcaserin \\
\hline Nicotine self-administration & $\downarrow$ & $\leftrightarrow$ & $\downarrow$ & $\downarrow$ \\
\hline Nicotine-induced hyperlocomotion & $\downarrow$ & $\leftrightarrow$ & $\downarrow$ & $\downarrow$ \\
\hline Nicotine interoceptive cue & $\uparrow / \downarrow$ & $\leftrightarrow$ & $\downarrow$ & $\downarrow$ \\
\hline $\begin{array}{l}\text { Reinstatement of nicotine-seeking } \\
\text { behaviour }\end{array}$ & $\downarrow$ & $\leftrightarrow$ & $\downarrow$ & $\downarrow$ \\
\hline Nicotine-conditioned place preference & $\downarrow$ & $\uparrow$ & NT & NT \\
\hline Nicotine-precipitated W/D (somatic) & NT & $\downarrow$ & $\leftrightarrow$ & $\leftrightarrow$ \\
\hline Nicotine-precipitated W/D (affective) & NT & $\downarrow$ & $\downarrow$ & NT
\end{tabular}

$\downarrow$, Reduced response; $\uparrow$, increased response; $\leftrightarrow$, no reliable effect; $\uparrow / \downarrow$, mixed effects reported; $\mathrm{NT}=$ not tested

${ }^{a}$ In the case of varenicline, bupropion and lorcaserin, each was assessed against reinstatement produced by a combination of nicotine prime and cues. RO 60-0175 was shown to be effective against reinstatement induced by either a nicotine prime or cues

${ }^{\mathrm{b}} W / D$ withdrawal/dependence

Doses of lorcaserin that reduce feeding behaviour and behavioural effects induced by nicotine in rats [131] result in plasma levels similar to those observed in people taking a therapeutic dose of lorcaserin for obesity [111], thus suggesting that dose regimens used in obesity treatment would be appropriate for testing lorcaserin in a smoking-cessation trial. However one disadvantage of using this drug is its potential interaction with $5-\mathrm{HT}_{2 \mathrm{~A}}$ receptors, thought to induce hallucinogenic effects. Moreover, it is as of yet unknown to what extent lorcaserin, along with other $5-\mathrm{HT}_{2 \mathrm{C}}$ agonists, occupies and activates the 5- $\mathrm{HT}_{2 \mathrm{C}}$ receptors at therapeutic exposure. However, due to lorcaserin being the first $5-\mathrm{HT}_{2 \mathrm{C}}$ receptor agonist with clinical approval, it is a preferable and viable method for the application of testing animal evidence in humans [111].

\section{Conclusions}

Nicotine exerts a wide range of effects on multiple neurotransmitter systems including ACh, GLU, DA, NA, 5-HT and GABA by acting on nAChRs; it is considered to be an extraordinary psychotropic drug as it is difficult to find another with such a pleiotropic action. The 5-HT pathway is implicated in nicotine dependence and may influence smoking cessation; the $5-\mathrm{HT}_{2 \mathrm{C}}$ receptor seems to be the most likely receptor to be involved.

The pharmacotherapy of nicotine addiction is still considered to be unsatisfactory, despite a large amount of data being produced on the neurobiological basis of withdrawal, action and dependence of nicotine. An increasing body of evidence has indicated that $5-\mathrm{HT}_{2 \mathrm{C}}$ neurotransmission is a critical neurological substrate in the process of smoking cessation or its role in the suppression of nicotine withdrawal in smokers. $5-\mathrm{HT}_{2 \mathrm{C}}$ receptor agonists could be useful in treating not only the wide 
range of behaviours produced by nicotine addiction, but also other drugs of abuse, because of the widespread influence of these receptors on behaviour. In conclusion, a more complete preclinical evaluation of the $5-\mathrm{HT}_{2 \mathrm{C}}$ receptor role in nicotine addiction will ultimately allow educated, proof-of-concept trials to test the concept that selective $5-\mathrm{HT}_{2 \mathrm{C}}$ agonists such as lorcaserin may be useful as adjunctive therapy.

Acknowledgments This work was supported by University of Malta funding scheme (GDG) and EU COST Action CM1103 "Structure-based drug design for diagnosis and treatment of neurological diseases: dissecting and modulating complex function in the monoaminergic systems of the brain" (GDG and PDD). SC. and LP. were supported by Erasmus placement scholarships.

\section{References}

1. Di Giovanni G, Esposito E, Di Matteo V. 5-HT2C receptors in the pathophysiology of CNS disease. The receptors. New York: Springer; 2011. p. 1-557.

2. Di Giovanni G, Di Matteo V, Esposito E. Serotonin-dopamine interaction: experimental evidence and therapeutic relevance. Progress in brain research, vol. 172. Amsterdam: Elsevier; 2008. p. 1-665.

3. Müller CP, Jacobs BL. Handbook of behavioral neurobiology of serotonin: handbook of behavioral neuroscience. 1st ed. Massachusetts: Academic Press; 2010. p. 836.

4. Hannon J, Hoyer D. Molecular biology of 5-HT receptors. Behav Brain Res. 2008;195: 198-213.

5. Hoyer D, Hannon JP, Martin GR. Molecular, pharmacological and functional diversity of 5-HT receptors. Pharmacol Biochem Behav. 2002;71(4):533-54.

6. Bonasera SJ, Tecott LH. Mouse models of serotonin receptor function: toward a genetic dissection of serotonin systems. Pharmacol Ther. 2000;88(2):133-42.

7. Koob GF. Drugs of abuse: anatomy, pharmacology and function of reward pathways. Trends Pharmacol Sci. 1992;13(5):177-84.

8. Brown AS, Gershon S. Dopamine and depression. J Neural Transm Gen Sect. 1993;91(2-3): 75-109.

9. Jenck F, et al. The role of 5-HT2C receptors in affective disorders. Expert Opin Investig Drugs. 1998;7(10):1587-99.

10. Di Matteo V, et al. Role of 5-HT2C receptors in the control of central dopamine function. Trends Pharmacol Sci. 2001;22(5):229-32.

11. Higgins GA, Fletcher PJ. Serotonin and drug reward: focus on 5-HT2C receptors. Eur J Pharmacol. 2003;480(1-3):151-62.

12. Giorgetti M, Tecott LH. Contributions of 5-HT(2C) receptors to multiple actions of central serotonin systems. Eur J Pharmacol. 2004;488(1-3):1-9.

13. Alex KD, Pehek EA. Pharmacologic mechanisms of serotonergic regulation of dopamine neurotransmission. Pharmacol Ther. 2007;113(2):296-320.

14. Di Giovanni G, Esposito E, Di Matteo V. 5-HT2C receptors in the pathophysiology of CNS disease. New York: Humana Press; 2011. p. 560.

15. Hoyer D, et al. International Union of Pharmacology classification of receptors for 5-hydroxytryptamine (Serotonin). Pharmacol Rev. 1994;46(2):157-203.

16. Barnes NM, Sharp T. A review of central 5-HT receptors and their function. Neuropharmacology. 1999;38(8):1083-152.

17. Di Giovanni G, Esposito E, Di Matteo V. Role of serotonin in central dopamine dysfunction. CNS Neurosci Ther. 2010;16(3):179-94.

18. Murphy DL, et al. How the serotonin story is being rewritten by new gene-based discoveries principally related to SLC6A4, the serotonin transporter gene, which functions to influence all cellular serotonin systems. Neuropharmacology. 2008;55(6):932-60. 
19. Thompson JH. Serotonin and the alimentary tract. Res Commun Chem Pathol Pharmacol. 1971;2(4):687-781.

20. Cirillo C, Vanden Berghe P, Tack J. Role of serotonin in gastrointestinal physiology and pathology. Minerva Endocrinol. 2011;36(4):311-24.

21. Feldberg W, Toh CC. Distribution of 5-hydroxytryptamine (serotonin, enteramine) in the wall of the digestive tract. J Physiol. 1953;119:352-62.

22. Costa M, et al. Neurons with 5-hydroxytryptamine-like immunoreactivity in the enteric nervous system: their visualization and reactions to drug treatment. Neuroscience. 1982;7:351-63.

23. Erspamer V, Asero B. Identification of enteramine, the specific hormone of the enterochromaffin cell system, as 5-hydroxytryptamine. Nature. 1952;169(4306):800-1.

24. Rapport MM, Green AA, Page IH. Serum vasoconstrictor (serotonin).4. Isolation and characterization. J Biol Chem. 1948;176(3):1243-51.

25. Twarog BM, Page IH. Serotonin content of some mammalian tissues and urine and a method for its determination. Am J Physiol. 1953;175(1):157-61.

26. Brodie BB, Pletscher A, Shore PA. Evidence that serotonin has a role in brain function. Science. 1955;122(3177):968.

27. Costa E, Aprison MH. Studies on the 5-hydroxytryptamine (serotonin) content in human brain. J Nerv Ment Dis. 1958;126(3):289-93.

28. Whitaker-Azmita PM. Serotonin and brain development: role in human developmental diseases. Brain Res Bull. 2001;56(5):479-85.

29. Abrams JK, et al. Anatomic and functional topography of the dorsal raphe nucleus. Ann N Y Acad Sci. 2004;1018:46-57.

30. Dahlström A, Fuxe K. Evidence for the existence of monoamine-containing neurons in the central nervous system I Demonstration of monoamines in the cell bodies of brain stem neurons. Acta Physiol Scand Suppl. 1964;(Suppl. 232):1-55.

31. Baker KG, Halliday GM, Tork I. Cytoarchitecture of the human dorsal raphe nucleus. J Comp Neurol. 1990;301(2):147-61.

32. Azmitia EC, Segal M. An autoradiographic analysis of the differential ascending projections of the dorsal and median raphe nuclei in the rat. J Comp Neurol. 1978;179(3): 641-67.

33. van der Kooy D, Hattori T. Dorsal raphe cells with collateral projections to the caudateputamen and substantia nigra: a fluorescent retrograde double labeling study in the rat. Brain Res. 1980;186(1):1-7.

34. Herve $\mathrm{D}$, et al. Serotonin axon terminals in the ventral tegmental area of the rat: fine structure and synaptic input to dopaminergic neurons. Brain Res. 1987;435(1-2):71-83.

35. Van Bockstaele EJ, Biswas A, Pickel VM. Topography of serotonin neurons in the dorsal raphe nucleus that send axon collaterals to the rat prefrontal cortex and nucleus accumbens. Brain Res. 1993;624(1-2):188-98.

36. Van Bockstaele EJ, Cestari DM, Pickel VM. Synaptic structure and connectivity of serotonin terminals in the ventral tegmental area: potential sites for modulation of mesolimbic dopamine neurons. Brain Res. 1994;647(2):307-22.

37. Moukhles H, et al. Quantitative and morphometric data indicate precise cellular interactions between serotonin terminals and postsynaptic targets in rat substantia nigra. Neuroscience. 1997;76(4):1159-71.

38. Hillegaart V. Functional topography of brain serotonergic pathways in the rat. Acta Physiol Scand Suppl. 1991;598:1-54.

39. Corvaja N, Doucet G, Bolam JP. Ultrastructure and synaptic targets of the raphe-nigral projection in the rat. Neuroscience. 1993;55(2):417-27.

40. Di Matteo V, et al. Serotonin control of central dopaminergic function: focus on in vivo microdialysis studies. Prog Brain Res. 2008;172:7-44.

41. Jacobs BL, Azmitia EC. Structure and function of the brain serotonin system. Physiol Rev. 1992;72(1):165-229.

42. Phillipson OT. Afferent projections to the ventral tegmental area of Tsai and interfascicular nucleus: a horseradish peroxidase study in the rat. J Comp Neurol. 1979;187(1):117-43. 
43. Esposito E, Di Matteo V, Di Giovanni G. Serotonin-dopamine interaction: an overview. Prog Brain Res. 2008;172:3-6.

44. Bowker RM, et al. Organization of descending serotonergic projections to the spinal cord. Prog Brain Res. 1982;57:239-65.

45. Bowker RM. The relationship between descending serotonin projections and ascending projections in the nucleus raphe magnus: a double labeling study. Neurosci Lett. 1986;70(3):348-53.

46. McMahon LL, Yoon KW, Chiappinelli VA. Nicotinic receptor activation facilitates gabaergic neurotransmission in the avian lateral spiriform nucleus. Neuroscience. 1994;59(3):689-98.

47. Fletcher PJ, Grottick AJ, Higgins GA. Differential effects of the 5-HT(2A) receptor antagonist M100907 and the 5-HT(2C) receptor antagonist SB242084 on cocaine-induced locomotor activity, cocaine self-administration and cocaine-induced reinstatement of responding. Neuropsychopharmacology. 2002;27(4):576-86.

48. Fletcher A, et al. Opposing effects of 5-HT2A and 5-HT2C receptor antagonists in the rat and mouse on premature responding in the five-choice serial reaction time test. Psychopharmacology. 2007;195:223-34.

49. Hjorth S, Magnusson T. The 5-HT 1A receptor agonist, 8-OH-DPAT, preferentially activates cell body 5-HT autoreceptors in rat brain in vivo. Naunyn Schmiedebergs Arch Pharmacol. 1988;338(5):463-71.

50. Di Giovanni G, et al. Central serotonin2C receptor: from physiology to pathology. Curr Top Med Chem. 2006;6(18):1909-25.

51. Di Giovanni G, et al. Serotonin involvement in the basal ganglia pathophysiology: could the 5-HT2C receptor be a new target for therapeutic strategies? Curr Med Chem. 2006;13(25):3069-81.

52. Fletcher PJ, Le AD, Higgins GA. Serotonin receptors as potential targets for modulation of nicotine use and dependence. Prog Brain Res. 2008;172:361-83.

53. Fletcher A, Higgins GA. Serotonin and reward-related behaviour: focus on 5-HT2C receptors. In: Di Giovanni G, Esposito E, Di Matteo V, editors. 5-HT2C receptors in the pathophysiology of CNS disease. New York: Springer; 2011. p. 293-324.

54. Di Matteo V, Esposito E, Di Giovanni G. Neurodegenerative disorders: from molecules to man (part 1). CNS Neurol Disord Drug Targets. 2007;6(6):375-6.

55. Markou A. Neurobiology of nicotine dependence. Philos Trans R Soc Biol Sci. 2008;363(1507):3159-68.

56. Clarke PBS, et al. Evidence that mesolimbic dopaminergic activation underlies the locomotor stimulant action of nicotine in rats. Journal of Pharmacology and Experimental Therapeutics. 1988;246(2):701-8.

57. Corrigall WA, Coen KM, Adamson KL. Self-administered nicotine activates the mesolimbic dopamine system through the ventral tegmental area. Brain Res. 1994;653(1-2):278-84.

58. Di Chiara G. Role of dopamine in the behavioural actions of nicotine related to addiction. Eur J Pharmacol. 2000;393(1-3):295-314.

59. Coppen A. The biochemistry of affective disorders. Br J Psychiatry. 1967;113(504):1237-64.

60. Seth $P$, et al. Nicotinic-serotonergic interactions in brain and behaviour. Pharmacol Biochem Behav. 2002;71(4):795-805.

61. Thomas KH, et al. Smoking cessation treatment and risk of depression, suicide, and self harm in the Clinical Practice Research Datalink: prospective cohort study. BMJ. 2013;347:f5704.

62. Balfour DJ, Ridley DL. The effects of nicotine on neural pathways implicated in depression: a factor in nicotine addiction? Pharmacol Biochem Behav. 2000;66(1):79-85.

63. Quattrocki E, Baird A, Yurgelun-Todd D. Biological aspects of the link between smoking and depression. Harv Rev Psychiatry. 2000;8(3):99-110.

64. Bitner RS, et al. Reduced nicotinic receptor-mediated antinociception following in vivo antisense knock-down in rat. Brain Res. 2000;871(1):66-74.

65. Bitner RS, Nikkel AL. Alpha-7 nicotinic receptor expression by two distinct cell types in the dorsal raphe nucleus and locus coeruleus of rat. Brain Res. 2002;938(1-2):45-54.

66. Cucchiaro G, Chaijale N, Commons KG. The dorsal raphe nucleus as a site of action of the antinociceptive and behavioral effects of the alpha4 nicotinic receptor agonist epibatidine. J Pharmacol Exp Ther. 2005;313(1):389-94. 
67. Cucchiaro G, Commons KG. Alpha 4 nicotinic acetylcholine receptor subunit links cholinergic to brainstem monoaminergic neurotransmission. Synapse. 2003;49(3):195-205.

68. Enkhbaatar P, et al. The inhibition of inducible nitric oxide synthase in ovine sepsis model. Shock. 2006;25(5):522-7.

69. Galindo-Charles L, et al. Serotoninergic dorsal raphe neurons possess functional postsynaptic nicotinic acetylcholine receptors. Synapse. 2008;62(8):601-15.

70. Li X, et al. Presynaptic nicotinic receptors facilitate monoaminergic transmission. J Neurosci. 1998;18(5):1904-12.

71. Mihailescu S, Guzman-Marin R, Drucker-Colin R. Nicotine stimulation of dorsal raphe neurons: effects on laterodorsal and pedunculopontine neurons. Eur Neuropsychopharmacol. 2001;11(5):359-66.

72. Chang B, et al. Nicotinic excitation of serotonergic projections from dorsal raphe to the nucleus accumbens. J Neurophysiol. 2011;106(2):801-8.

73. Engberg G, et al. Nicotine inhibits firing activity of dorsal raphe 5-HT neurones in vivo. Naunyn Schmiedebergs Arch Pharmacol. 2000;362(1):41-5.

74. Touiki K, et al. Effects of tobacco and cigarette smoke extracts on serotonergic raphe neurons in the rat. Neuroreport. 2007;18(9):925-9.

75. Ma Z, et al. Effects on serotonin of (-)nicotine and dimethylphenylpiperazinium in the dorsal raphe and nucleus accumbens of freely behaving rats. Neuroscience. 2005;135(3):949-58.

76. Ribeiro EB, et al. Effects of systemic nicotine on serotonin release in rat brain. Brain Res. 1993;621(2):311-8.

77. Ranade SP, Mainen ZF. Transient firing of dorsal raphe neurons encodes diverse and specific sensory, motor, and reward events. J Neurophysiol. 2009;102(5):3026-37.

78. Summers KL, Lippiello P, Giacobini E. A microdialysis study of the effects of the nicotinic agonist RJR-2403 on cortical release of acetylcholine and biogenic amines. Neurochem Res. 1996;21(10):1181-6.

79. Schwartz RD, Lehmann J, Kellar KJ. Presynaptic nicotinic cholinergic receptors labeled by $[3 \mathrm{H}]$ acetylcholine on catecholamine and serotonin axons in brain. $\mathbf{J}$ Neurochem. 1984;42(5):1495-8.

80. Reuben M, Clarke PB. Nicotine-evoked [3H]5-hydroxytryptamine release from rat striatal synaptosomes. Neuropharmacology. 2000;39(2):290-9.

81. Yu ZJ, Wecker L. Chronic nicotine administration differentially affects neurotransmitter release from rat striatal slices. J Neurochem. 1994;63(1):186-94.

82. Takahashi $\mathrm{H}$, et al. Nicotine increases stress-induced serotonin release by stimulating nicotinic acetylcholine receptor in rat striatum. Synapse. 1998;28(3):212-9.

83. Lendvai B, et al. Differential mechanisms involved in the effect of nicotinic agonists DMPP and lobeline to release [3H]5-HT from rat hippocampal slices. Neuropharmacology. 1996;35(12):1769-77.

84. Kenny PJ, File SE, Neal MJ. Evidence for a complex influence of nicotinic acetylcholine receptors on hippocampal serotonin release. J Neurochem. 2000;75(6):2409-14.

85. Benwell ME, Balfour DJ. Effects of nicotine administration and its withdrawal on plasma corticosterone and brain 5-hydroxyindoles. Psychopharmacology (Berl). 1979;63(1):7-11.

86. Takada Y, et al. Changes in the central and peripheral serotonergic system in rats exposed to water-immersion restrained stress and nicotine administration. Neurosci Res. 1995;23(3): 305-11.

87. Matta SG, et al. Guidelines on nicotine dose selection for in vivo research. Psychopharmacology (Berl). 2007;190(3):269-319.

88. Crooks PA, Dwoskin LP. Contribution of CNS nicotine metabolites to the neuropharmacological effects of nicotine and tobacco smoking. Biochem Pharmacol. 1997;54(7): 743-53.

89. Clemens KJ, et al. The addition of five minor tobacco alkaloids increases nicotine-induced hyperactivity, sensitization and intravenous self-administration in rats. Int $\mathrm{J}$ Neuropsychopharmacol. 2009;12(10):1355-66.

90. Khalki $\mathrm{H}$, et al. A tobacco extract containing alkaloids induces distinct effects compared to pure nicotine on dopamine release in the rat. Neurosci Lett. 2013;544:85-8. 
91. Guillem K, et al. Monoamine oxidase inhibition dramatically increases the motivation to self-administer nicotine in rats. J Neurosci. 2005;25(38):8593-600.

92. Pazos A, Cortes R, Palacios JM. Quantitative autoradiographic mapping of serotonin receptors in the rat-brain. 2. Serotonin-2 receptors. Brain Res. 1985;346(2):231-49.

93. Pompeiano M, Palacios JM, Mengod G. Distribution of the serotonin 5-Ht2 receptor family messenger-Rnas-comparison between 5- $\mathrm{Ht}(2 \mathrm{a})$ and 5- $\mathrm{Ht}(2 \mathrm{c})$ receptors. Mol Brain Res. 1994;23(1-2):163-78.

94. Bubser M, et al. Distribution of serotonin 5-HT(2A) receptors in afferents of the rat striatum. Synapse. 2001;39(4):297-304.

95. Willins DL, Meltzer HY. Serotonin 5-HT2C agonists selectively inhibit morphine-induced dopamine efflux in the nucleus accumbens. Brain Res. 1998;781(1-2):291-9.

96. Cornea-Hébert V, et al. Cellular and subcellular distribution of the serotonin 5- $\mathrm{HT}_{2 \mathrm{~A}}$ receptor in the central nervous system of adult rat. J Comp Neurol. 1999;409(2):187-209.

97. Doherty MD, Pickel VM. Ultrastructural localization of the serotonin 2 A receptor in dopaminergic neurons in the ventral tegmental area. Brain Res. 2000;864(2):176-85.

98. Nocjar C, Roth BL, Pehek EA. Localization of 5-HT(2A) receptors on dopamine cells in subnuclei of the midbrain A10 cell group. Neuroscience. 2002;111(1):163-76.

99. Olausson P, et al. Effects of 5-HT1A and 5-HT2 receptor agonists on the behavioral and neurochemical consequences of repeated nicotine treatment. Eur J Pharmacol. 2001; 420(1):45-54.

100. Batman AM, Munzar P, Beardsley PM. Attenuation of nicotine's discriminative stimulus effects in rats and its locomotor activity effects in mice by serotonergic $5-\mathrm{HT} 2 \mathrm{~A} / 2 \mathrm{C}$ receptor agonists. Psychopharmacology (Berl). 2005;179(2):393-401.

101. Zaniewska M, et al. Effects of the serotonin 5-HT2A and 5-HT2C receptor ligands on the discriminative stimulus effects of nicotine in rats. Eur J Pharmacol. 2007;571(2-3):156-65.

102. Arnt J. Characterization of the discriminative stimulus properties induced by $5-\mathrm{HT} 1$ and 5-HT2 agonists in rats. Pharmacol Toxicol. 1989;64(2):165-72.

103. Nichols DE. Hallucinogens. Pharmacol Ther. 2004;101(2):131-81.

104. Porras G, et al. 5-HT2A and 5-HT2C/2B receptor subtypes modulate dopamine release induced in vivo by amphetamine and morphine in both the rat nucleus accumbens and striatum. Neuropsychopharmacology. 2002;26(3):311-24.

105. Auclair A, et al. Role of serotonin $2 \mathrm{~A}$ receptors in the D-amphetamine-induced release of dopamine: comparison with previous data on alphalb-adrenergic receptors. J Neurochem. 2004;91(2):318-26.

106. O'Neill MF, Heron-Maxwell CL, Shaw G. 5-HT2 receptor antagonism reduces hyperactivity induced by amphetamine, cocaine, and MK-801 but not D1 agonist C-APB. Pharmacol Biochem Behav. 1999;63(2):237-43.

107. Herin DV, et al. Elevated expression of serotonin 5-HT(2A) receptors in the rat ventral tegmental area enhances vulnerability to the behavioral effects of cocaine. Front Psychiatry. 2013;4:2.

108. Levin ED, et al. Ketanserin, a 5-HT2 receptor antagonist, decreases nicotine selfadministration in rats. Eur J Pharmacol. 2008;600(1-3):93-7.

109. Fletcher PJ, et al. Effects of the 5-HT2C receptor agonist Ro60-0175 and the 5-HT2A receptor antagonist M100907 on nicotine self-administration and reinstatement. Neuropharmacology. 2012;62(7):2288-98.

110. Higgins GA, Sellers EM, Fletcher PJ. From obesity to substance abuse: therapeutic opportunities for 5-HT2C receptor agonists. Trends Pharmacol Sci. 2013;34(10):560-70.

111. Bubar MJ, et al. Validation of a selective serotonin 5-HT2C receptor antibody for utilization in fluorescence immunohistochemistry studies. Brain Res. 2005;1063(2):105-13.

112. Bubar MJ, Cunningham KA. Distribution of serotonin 5-HT2C receptors in the ventral tegmental area. Neuroscience. 2007;146(1):286-97.

113. Prisco S, Pagannone S, Esposito E. Serotonin-dopamine interaction in the rat ventral tegmental area: an electrophysiological study in vivo. J Pharmacol Exp Ther. 1994;271(1):83-90.

114. Di Giovanni G, et al. Selective blockade of serotonin-2C/2B receptors enhances mesolimbic and mesostriatal dopaminergic function: a combined in vivo electrophysiological and microdialysis study. Neuroscience. 1999;91(2):587-97. 
115. De Deurwaerdere P, et al. Multiple controls exerted by 5-HT2C receptors upon basal ganglia function: from physiology to pathophysiology. Exp Brain Res. 2013;230(4):477-511.

116. Martin JR, et al. 5-HT2C receptor agonists: pharmacological characteristics and therapeutic potential. J Pharmacol Exp Ther. 1998;286(2):913-24.

117. Millan MJ, Dekeyne A, Gobert A. Serotonin (5-HT)2C receptors tonically inhibit dopamine (DA) and noradrenaline (NA), but not 5-HT, release in the frontal cortex in vivo. Neuropharmacology. 1998;37(7):953-5.

118. Di Matteo V, et al. SB 242084, a selective serotonin2C receptor antagonist, increases dopaminergic transmission in the mesolimbic system. Neuropharmacology. 1999;38(8): 1195-205.

119. Di Matteo V, et al. Biochemical and electrophysiological evidence that RO 60-0175 inhibits mesolimbic dopaminergic function through serotonin(2C) receptors. Brain Res. 2000; 865(1):85-90.

120. Gobert A, et al. Serotonin(2C) receptors tonically suppress the activity of mesocortical dopaminergic and adrenergic, but not serotonergic, pathways: a combined dialysis and electrophysiological analysis in the rat. Synapse. 2000;36(3):205-21.

121. Kennett GA, et al. In vitro and in vivo profile of SB 206553, a potent 5-HT2C/5-HT2B receptor antagonist with anxiolytic-like properties. Br J Pharmacol. 1996;117(3):427-34.

122. Kennett GA, et al. SB 242084, a selective and brain penetrant 5-HT2C receptor antagonist. Neuropharmacology. 1997;36(4-5):609-20.

123. Di Matteo V, et al. Selective blockade of serotonin $2 \mathrm{C} / 2 \mathrm{~B}$ receptors enhances dopamine release in the rat nucleus accumbens. Neuropharmacology. 1998;37(2):265-72.

124. De Deurwaerdere $\mathrm{P}$, et al. Constitutive activity of the serotonin $2 \mathrm{C}$ receptor inhibits in vivo dopamine release in the rat striatum and nucleus accumbens. J Neurosci. 2004;24(13): 3235-41.

125. Pozzi L, et al. Stimulation of 5-hydroxytryptamine (5-HT(2C) ) receptors in the ventrotegmental area inhibits stress-induced but not basal dopamine release in the rat prefrontal cortex. J Neurochem. 2002;82(1):93-100.

126. Hutson $\mathrm{PH}$, et al. Activation of mesolimbic dopamine function by phencyclidine is enhanced by 5-HT(2C/2B) receptor antagonists: neurochemical and behavioural studies. Neuropharmacology. 2000;39(12):2318-28.

127. Porras G, et al. Central serotonin 4 receptors selectively regulate the impulse-dependent exocytosis of dopamine in the rat striatum: in vivo studies with morphine, amphetamine and cocaine. Neuropharmacology. 2002;43(7):1099-109.

128. Quarta D, Naylor GG, Stolerman IP. The serotonin 2C receptor agonist Ro-60-0175 attenuates effects of nicotine in the five-choice serial reaction time task and in drug discrimination. Psychopharmacology (Berl). 2007;193:391-402.

129. Grottick AJ, Corrigall WA, Higgins GA. Activation of 5-HT(2C) receptors reduces the locomotor and rewarding effects of nicotine. Psychopharmacology (Berl). 2001;157(3):292-8.

130. Higgins GA, et al. Evaluation of chemically diverse 5-HT(2)c receptor agonists on behaviours motivated by food and nicotine and on side effect profiles. Psychopharmacology (Berl). 2012;226(3):475-90.

131. Grottick AJ, Fletcher PJ, Higgins GA. Studies to investigate the role of 5-HT(2C) receptors on cocaine- and food-maintained behavior. J Pharmacol Exp Ther. 2000;295(3):1183-91.

132. Neisewander JL, Acosta JI. Stimulation of 5-HT2C receptors attenuates cue and cocaine-primed reinstatement of cocaine-seeking behavior in rats. Behav Pharmacol. 2007;18(8):791-800.

133. Pockros LA, et al. Blockade of 5-HT2A receptors in the medial prefrontal cortex attenuates reinstatement of cue-elicited cocaine-seeking behavior in rats. Psychopharmacology (Berl). 2010;213(2-3):307-20.

134. Tomkins DM, et al. An investigation of the role of 5-HT(2C) receptors in modifying ethanol self-administration behaviour. Pharmacol Biochem Behav. 2002;71(4):735-44.

135. Levin ED, et al. Lorcaserin, a 5-HT2C agonist, decreases nicotine self-administration in female rats. J Pharmacol Exp Ther. 2011;338(3):890-6.

136. Ji SP, et al. Disruption of PTEN coupling with 5-HT2C receptors suppresses behavioral responses induced by drugs of abuse. Nat Med. 2006;12(3):324-9. 
137. Hayes DJ, Mosher TM, Greenshaw AJ. Differential effects of 5-HT2C receptor activation by WAY 161503 on nicotine-induced place conditioning and locomotor activity in rats. Behav Brain Res. 2009;197(2):323-30.

138. Zaniewska M, McCreary AC, Filip M. Interactions of serotonin (5-HT)2 receptor-targeting ligands and nicotine: locomotor activity studies in rats. Synapse. 2009;63(8):653-61.

139. Di Matteo V, Pierucci M, Esposito E. Selective stimulation of serotonin2C receptors blocks the enhancement of striatal and accumbal dopamine release induced by nicotine administration. J Neurochem. 2004;89(2):418-29.

140. Pierucci M, Di Matteo V, Esposito E. Stimulation of serotonin2C receptors blocks the hyperactivation of midbrain dopamine neurons induced by nicotine administration. J Pharmacol Exp Ther. 2004;309(1):109-18.

141. Di Giovanni G, et al. m-Chlorophenylpiperazine excites non-dopaminergic neurons in the rat substantia nigra and ventral tegmental area by activating serotonin-2C receptors. Neuroscience. 2001;103(1):111-6.

142. Chevalier G, et al. Disinhibition as a basic process in the expression of striatal functions. I. The striato-nigral influence on tecto-spinal/tecto-diencephalic neurons. Brain Res. 1985;334(2):215-26.

143. Maurice N, et al. Relationships between the prefrontal cortex and the basal ganglia in the rat: physiology of the cortico-nigral circuits. J Neurosci. 1999;19(11):4674-81.

144. Beyeler A, et al. Stimulation of serotonin2C receptors elicits abnormal oral movements by acting on pathways other than the sensorimotor one in the rat basal ganglia. Neuroscience. 2010;169(1):158-70.

145. Navailles S, et al. In vivo evidence that 5-HT2C receptor antagonist but not agonist modulates cocaine-induced dopamine outflow in the rat nucleus accumbens and striatum. Neuropsychopharmacology. 2004;29(2):319-26.

146. Olausson P, Engel JA, Soderpalm B. Behavioral sensitization to nicotine is associated with behavioral disinhibition; counteraction by citalopram. Psychopharmacology (Berl). 1999; 142(2):111-9.

147. Kenny PJ, Markou A. Neurobiology of the nicotine withdrawal syndrome. Pharmacol Biochem Behav. 2001;70(4):531-49.

148. Zaniewska M, et al. Effects of serotonin (5-HT)2 receptor ligands on depression-like behavior during nicotine withdrawal. Neuropharmacology. 2010;58(7):1140-6.

149. Anderson JE, et al. Treating tobacco use and dependence: an evidence-based clinical practice guideline for tobacco cessation. Chest. 2002;121(3):932-41.

150. Jain A. Treating nicotine addiction. BMJ. 2003;327(7428):1394-5.

151. Shahan TA, et al. Comparing the reinforcing efficacy of nicotine containing and de-nicotinized cigarettes: a behavioral economic analysis. Psychopharmacology (Berl). 1999;147(2):210-6.

152. Mucha RF, Geier A, Pauli P. Modulation of craving by cues having differential overlap with pharmacological effect: evidence for cue approach in smokers and social drinkers. Psychopharmacology (Berl). 1999;147(3):306-13.

153. Dols M, et al. Smokers can learn to influence their urge to smoke. Addict Behav. 2000; 25(1):103-8.

154. Cryan JF, et al. Non-nicotinic neuropharmacological strategies for nicotine dependence: beyond bupropion. Drug Discov Today. 2003;8(22):1025-34.

155. Ascher JA, et al. Bupropion: a review of its mechanism of antidepressant activity. J Clin Psychiatry. 1995;56(9):395-401.

156. Rigotti NA. Clinical practice. Treatment of tobacco use and dependence. N Engl J Med. 2002;346(7):506-12.

157. Coe JW, et al. Varenicline: an alpha4beta2 nicotinic receptor partial agonist for smoking cessation. J Med Chem. 2005;48(10):3474-7.

158. Eisenberg MJ, et al. Pharmacotherapies for smoking cessation: a meta-analysis of randomized controlled trials. CMAJ. 2008;179(2):135-44.

159. Rollema H, et al. Rationale, pharmacology and clinical efficacy of partial agonists of alpha4beta2 nACh receptors for smoking cessation. Trends Pharmacol Sci. 2007;28(7):316-25. 
160. Slemmer JE, Martin BR, Damaj MI. Bupropion is a nicotinic antagonist. J Pharmacol Exp Ther. 2000;295(1):321-7.

161. Cooper BR, et al. Evidence that the acute behavioral and electrophysiological effects of bupropion (Wellbutrin) are mediated by a noradrenergic mechanism. Neuropsychopharmacology. 1994;11(2):133-41.

162. Mansvelder HD, et al. Bupropion inhibits the cellular effects of nicotine in the ventral tegmental area. Biochem Pharmacol. 2007;74(8):1283-91.

163. Dong J, Blier P. Modification of norepinephrine and serotonin, but not dopamine, neuron firing by sustained bupropion treatment. Psychopharmacology (Berl). 2001;155(1):52-7.

164. Reperant C, et al. Effect of the [alpha]4[beta]2* nicotinic acetylcholine receptor partial agonist varenicline on dopamine release in [beta] 2 knock-out mice with selective re-expression of the [beta] 2 subunit in the ventral tegmental area. Neuropharmacology. 2010;58(2): $346-50$.

165. Rollema H, et al. Preclinical pharmacology of the alpha4beta2 nAChR partial agonist varenicline related to effects on reward, mood and cognition. Biochem Pharmacol. 2009; 78(7):813-24.

166. Rollema H, et al. Effect of co-administration of varenicline and antidepressants on extracellular monoamine concentrations in rat prefrontal cortex. Neurochem Int. 2011;58(1):78-84.

167. Mills EJ, et al. Efficacy of pharmacotherapies for short-term smoking abstinance: a systematic review and meta-analysis. Harm Reduct J. 2009;6:25.

168. US Food and Drug Administration CfDEaR. Varenicline (marketed as Chantix) information. 2008. Washington (DC): US Department of Health and Human Services. www.fda.gov/ CDER/Drug/infopage/varenicline/default.htm. Accessed 12 Dec 2010.

169. Hall SM, et al. Nortriptyline and cognitive-behavioral therapy in the treatment of cigarette smoking. Arch Gen Psychiatry. 1998;55(8):683-90.

170. Prochazka AV, et al. A randomized trial of nortriptyline for smoking cessation. Arch Intern Med. 1998;158(18):2035-9.

171. Hall SM, et al. Psychological intervention and antidepressant treatment in smoking cessation. Arch Gen Psychiatry. 2002;59(10):930-6.

172. Edwards NB, et al. Doxepin as an adjunct to smoking cessation: a double-blind pilot study. Am J Psychiatry. 1989;146(3):373-6.

173. Dalack GW, et al. Mood, major depression, and fluoxetine response in cigarette smokers. Am J Psychiatry. 1995;152(3):398-403.

174. Schneider NG, et al. Efficacy of buspirone in smoking cessation: a placebo-controlled trial. Clin Pharmacol Ther. 1996;60(5):568-75.

175. Farley AC, et al. Interventions for preventing weight gain after smoking cessation. Cochrane Database Syst Rev. 2012;1, CD006219.

176. Dahlstrom A, Fuxe K. Localization of monoamines in the lower brain stem. Experientia. 1964;20(7):398-9. 